\title{
Automatic estimation of aquifer parameters using long-term water supply pumping and injection records
}

\author{
Ning Luo ${ }^{1}$ - Walter A. Illman ${ }^{1}$ \\ Received: 12 August 2015 / Accepted: 19 March 2016 /Published online: 19 April 2016 \\ (C) The Author(s) 2016. This article is published with open access at Springerlink.com
}

\begin{abstract}
Analyses are presented of long-term hydrographs perturbed by variable pumping/injection events in a confined aquifer at a municipal water-supply well field in the Region of Waterloo, Ontario (Canada). Such records are typically not considered for aquifer test analysis. Here, the water-level variations are fingerprinted to pumping/injection rate changes using the Theis model implemented in the WELLS code coupled with PEST. Analyses of these records yield a set of transmissivity $(T)$ and storativity $(S)$ estimates between each monitoring and production borehole. These individual estimates are found to poorly predict water-level variations at nearby monitoring boreholes not used in the calibration effort. On the other hand, the geometric means of the individual $T$ and $S$ estimates are similar to those obtained from previous pumping tests conducted at the same site and adequately predict water-level variations in other boreholes. The analyses reveal that long-term municipal water-level records are amenable to analyses using a simple analytical solution to estimate aquifer parameters. However, uniform parameters estimated with analytical solutions should be considered as first rough estimates. More accurate hydraulic parameters should be obtained by calibrating a three-dimensional numerical model that rigorously captures the complexities of the site with these data.
\end{abstract}

Electronic supplementary material The online version of this article (doi:10.1007/s10040-016-1407-x) contains supplementary material, which is available to authorized users.

Ning Luo

nluo1222@gmail.com

1 Department of Earth and Environment Sciences, University of Waterloo, Waterloo, Ontario N2L 3G1, Canada
Keywords Aquifer properties · Long-term water-level records · Analytical solution - Groundwater management . Canada

\section{Introduction}

Planning for the optimized use of groundwater resources is of paramount importance to water managers worldwide in the face of increased demands on groundwater resources, the protection of groundwater resources from contamination, and the increasing energy costs of community water systems. The optimized design and management of groundwater-based water systems requires the accurate estimation of transmissivity $(T)$ and storativity $(S)$, which are two important hydraulic parameters in predicting groundwater flow. Traditionally, the estimation of $T$ and $S$ is performed through the analysis of pumping tests, in which drawdown data are analyzed using analytical or numerical models. The Theis (1935) solution is the first analytical model developed for transient analysis of a pumping test in a confined aquifer, but numerous type curve solutions have since been developed over the next few decades for different aquifer types and boundary conditions (e.g., Hantush and Jacob 1955; Neuman 1974; Moench 1997; Mathias and Butler 2006; Mishra and Neuman 2011). The application of these analytical models is sometimes restricted in complex hydrogeological conditions, where some features that significantly affect groundwater flows are not considered (e.g., Mansour et al. 2011). Although the use of analytical models may lead to good matches between observed drawdowns and type curves, the estimated hydraulic properties may be scenario-dependent-for example, $\mathrm{Wu}$ et al. (2005) demonstrated that the conventional analysis of aquifer tests yields biased $T$ estimates that evolved with time and depended on the location of monitoring boreholes, and the 
estimated $S$ is mainly affected by the geology (i.e., heterogeneity) between the water-supply and monitoring boreholes.

Another important issue is that planning and conducting these tests within a municipal well field can be expensive, time-consuming, and impractical. For example, it is logistically infeasible to cease pumping/injection at a municipal well field to conduct a dedicated pumping test, considering that municipal water supply cannot be interrupted, and pressure influences induced by neighboring water-supply boreholes can affect results in uncertain ways (Harp and Vesselinov 2011).

Yeh and Lee (2007) suggested that existing long-term pumping/injection events and water-level records within a municipal well field could be used for the estimation of hydraulic parameters. In particular, existing hydrographs that have been affected by various water-supply and injection boreholes at different pumping/injection rates over an extended period can be readily obtained from contaminant monitoring or municipal water-supply well sites.

Such pumping/injection events and hydrographs have not been analyzed, except by Harp and Vesselinov (2011). In particular, they analyzed individual hydrographs by simulating drawdowns in monitoring boreholes by decomposing pumping rate variations from water-supply boreholes. In doing so, information about large-scale aquifer structures (i.e., heterogeneity) that inhibit or promote pressure propagation were identified. Also, a minimally parameterized analytical model (Theis 1935) was utilized in their research to estimate the $T$ and $S$ between each water-supply and monitoring borehole. However, the use of simple analytical solutions yields zero resolution on aquifer heterogeneity, but it is computationally efficient and able to provide fundamental insights into aquifer pressure responses (Harp and Vesselinov 2011). As concluded by Harp and Vesselinov (2011), analyses of existing hydrographs provided several significant advantages in characterizing aquifer properties compared with datasets generated through dedicated pumping tests. In particular, such records provide a large number of observations over time, which helps to minimize the effect of measurement errors. Also, long-term pumping of multiple water-supply boreholes stress aquifers more intensively, which provides the essential conditions to propagate pressure responses at a larger distance than typical pumping tests, rendering the analysis of drawdown records possible. Furthermore, estimated parameters represent aquifer properties during existing pumping/ injection events and are helpful in predicting groundwater flow when planning and operating water-supply well fields.

Harp and Vesselinov (2011) proposed a new approach for long-term hydrograph analysis, and they applied this approach to identify pumping influences of individual water-supply boreholes in water-level variations observed at monitoring boreholes using an approximately 5 -year record from a field site in New Mexico, USA. Although several sets of $T$ and $S$ were obtained, those parameters were not validated in their study.

This paper presents an analysis of complex long-term water-supply pumping/injection events and water-level records from the Mannheim East Well Field located in the Region of Waterloo, Ontario, Canada, utilizing the approach developed by Harp and Vesselinov (2011). The feasibility of this new approach is tested using a large number of water-supply boreholes and with more complex pumping and injection sequences (only pumping was considered by Harp and Vesselinov (2011)). The estimated parameters are also compared to those derived by other means and are used to predict water-level variations at nearby locations.

The primary purpose of this work is to show that these long-term pumping/injection events and water-level variation records are amenable to this type of analysis. Such a study is necessary before applying these data to characterize aquifers in greater detail using a more sophisticated numerical inverse model. Moreover, the results obtained from this study could also be used to guide the development and calibration of a more sophisticated groundwater flow and transport model at the site.

\section{Site description}

The Region of Waterloo (Region), located approximately $100 \mathrm{~km}$ west of Toronto in southeast Ontario, is the largest municipal user of groundwater ( $80 \%$ of total water supply) in Canada. There are more than 40 well fields with more than 100 water-supply boreholes operating within the Region. In order to manage the pumping/injection rates of water-supply boreholes and to make sure that they are within the capacity of the pumped aquifer, a monitoring network has been installed in each well field. Other than quantifying water demand and usage, data collected from these monitoring networks are also used to improve the hydraulic characterization of regional groundwater flow models (Golder Associates 2011).

\section{Description of municipal well fields}

The analysis presented in this paper focuses on the Mannheim East Well Field located in the southwest area of the city of Kitchener, Ontario, Canada. Currently, a total of 13 watersupply boreholes operate within this well field, and the distribution of these boreholes as well as 14 monitoring boreholes considered in this study are shown in Fig. 1c and are listed in Table 1. Figure 1a shows how the location of the Region relates to Canada and the US, and Fig. 1b indicates the study area within the Region. The Mannheim East Well Field is subdivided into three smaller well sites, which are identified as Mannheim East, Peaking, and Aquifer Storage and Recovery (ASR). According to Golder Associates (2011), 
Fig. 1 The location of study area as well as the distribution of boreholes utilized in this study. a The location of the Region of Waterloo in relation to Canada and the US, $\mathbf{b}$ the location of the Mannheim East Well Field within the Region of Waterloo, $\mathbf{c}$ the distribution of water-supply and monitoring boreholes in the study area (a)

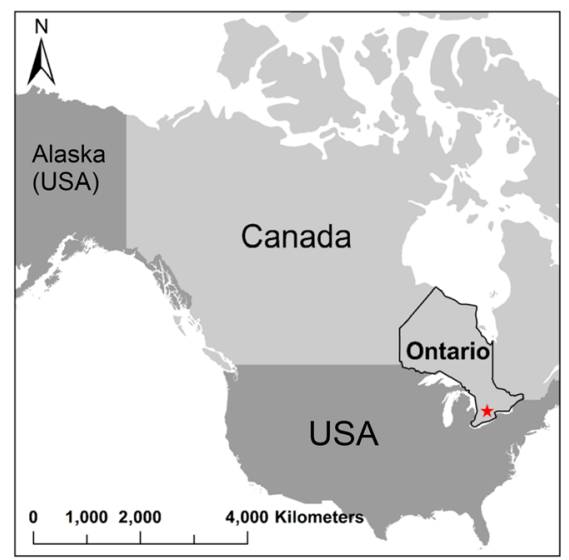

(b)

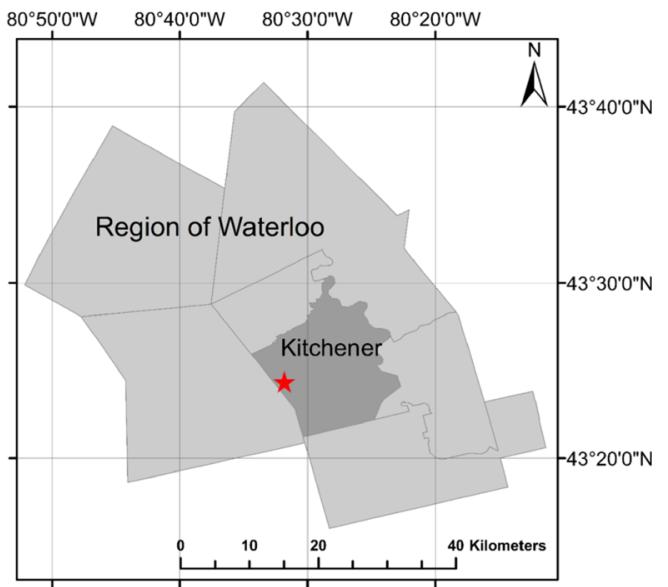

A

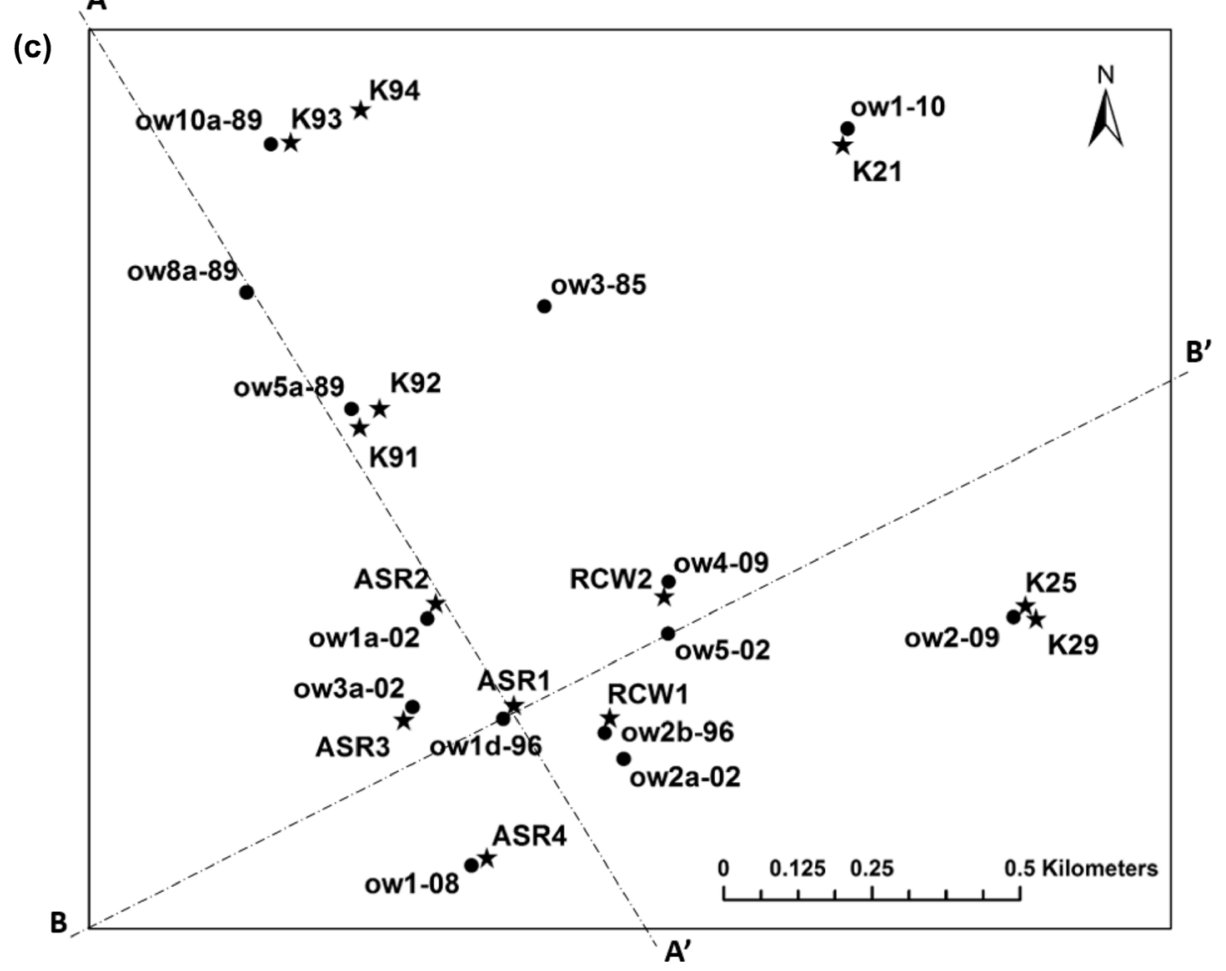

Mannheim East is the first well site that has been constructed in the eastern portion of the study area, and water-supply boreholes (K21, K25, and K29) at this site are used continuously to maintain groundwater supply with relatively constant pumping rates. Water-supply boreholes (K91, K92, K93, and K94) installed at the Peaking site located in the northwest portion of the study site are used seasonally during periods of high municipal water demand.

The ASR well site constructed in the southwest of the study area is the newest. This well site is designed to inject and store treated water from the Grand River during low water demand periods, and the stored water is extracted during high demand periods. Compared with the other two well sites, the ASR well system includes a great number of water-supply boreholes along with a more complex pumping/injection regime. In particular, the water-supply boreholes RCW1 and RCW2 are only used for pumping, while boreholes ASR1 through ASR4 are used for both injection and pumping. In order to maintain an adequate water supply when there is a significant drawdown of water level at the pumped borehole, all of these water-supply boreholes are screened at the bottom of the aquifer at an elevation range of approximately 315 325 masl.

Fourteen monitoring boreholes selected and analyzed in this study (ow2-09, ow1-10, ow3-85, ow5a-89, ow8a-89, ow10a-89, ow1d-96, ow2b-96, ow1a-02, ow2a-02, ow3a02, ow5-02, ow1-08, and ow4-09) are concentrated within the production areas, as shown in Fig. 1c. These 14 
Table 1 List of water-supply and water-level monitoring boreholes at each subdivided well site

\begin{tabular}{llll}
\hline Borehole type & \multicolumn{2}{l}{ Subdivided well sites } \\
\cline { 2 - 4 } & Mannheim East & Peaking & ASR \\
\hline Water supply & K21 & K91 & ASR1 \\
& K29 & K92 & ASR2 \\
& & K93 & ASR3 \\
& & K94 & ASR4 \\
Water-level monitoring & ow2-09 & & RCW1 \\
& ow1-10 & ow3-85 & ow1d-96 \\
& & ow5a-89 & ow2b-96 \\
& & ow8a-89 & ow1a-02 \\
& & ow10a-89 & ow2a-02 \\
& & & ow3a-02 \\
& & & ow5-02 \\
& & & ow1-08 \\
& & & ow4-09 \\
\hline
\end{tabular}

monitoring boreholes are screened within the same elevation range as the water-supply boreholes, and pressure transducers are placed in all of these boreholes to automatically collect water-level data. The distance between each water-supply and monitoring borehole ranges from several meters to more than $1 \mathrm{~km}$, and these values are summarized in Table 2 based on the spatial coordinates of boreholes obtained from the Water Resources Analysis System (WRAS+) database (Regional Municipality of Waterloo 2014).

\section{Local geology and hydrogeology}

The Mannheim East Well Field is located within the core area of the Waterloo Moraine, which is classified as a kame moraine and formed by numerous advances and retreats of ice lobes during the Wisconsinian glaciation stage (Martin and Frind 1998). These repeating glacial events resulted in a complex depositional pattern within the moraine, where outwash sands and gravels are separated by silt and clayrich tills.

Based on the geological investigation of the Waterloo Moraine by Karrow (1993), four major glacial tills considered to be aquitards, have been identified throughout the moraine (from youngest to oldest, they are Tavistock/Port Stanley Till, Maryhill Till, Catfish Creek Till, and Pre-Catfish Creek). Coarse grain deposits are found above, in-between, and below Maryhill Till and Catfish Creek Till. These deposits form major aquifers (aquifers 1, 2, and 3 from the youngest to the oldest in age) within the moraine.

The multiple-aquifer/aquitard system has been modeled (Terraqua Investigations 1995; Martin and Frind 1998) in order to better simulate groundwater flow within the moraine and improve groundwater management. Most recently, a three-dimensional (3D) mapping of surficial deposits of the Waterloo Moraine has been undertaken by Bajc and Shirota (2007) which resulted in a 3D geological model. This model, involving a finer description of stratification, provided a more detailed conceptual hydrogeological model.

In this paper, a simple 3D hydrogeological model of the study area is built based on existing borehole logs, and two cross-sectional maps are shown in Fig. 2 (see locations of A-

Table 2 Distances ( $\mathrm{m}$ ) between each pair of water-supply and monitoring boreholes

\begin{tabular}{|c|c|c|c|c|c|c|c|c|c|c|c|c|c|}
\hline \multirow{2}{*}{$\begin{array}{l}\text { Monitoring } \\
\text { boreholes }\end{array}$} & \multicolumn{13}{|c|}{ Water-supply boreholes } \\
\hline & K21 & $\mathrm{K} 25$ & K29 & K91 & K92 & K93 & K94 & ASR1 & ASR2 & ASR3 & ASR4 & RCW1 & RCW2 \\
\hline ow2-09 & 842.98 & 6.93 & 24.36 & $1,165.32$ & $1,141.68$ & $1,469.92$ & $1,404.16$ & 877.85 & 994.99 & $1,065.32$ & $1,000.92$ & 724.21 & 609.32 \\
\hline ow1-10 & 19.03 & 855.33 & 882.51 & 943.26 & 897.61 & 920.38 & 803.88 & $1,104.24$ & $1,038.89$ & $1,226.74$ & $1,354.25$ & $1,053.68$ & 830.29 \\
\hline ow3-85 & 573.17 & 957.41 & 984.36 & 373.10 & 327.22 & 509.81 & 454.17 & 675.55 & 533.96 & 737.72 & 936.66 & 703.43 & 530.96 \\
\hline ow5a-89 & 939.99 & $1,162.27$ & $1,185.54$ & 5.87 & 40.90 & 492.27 & 532.01 & 539.03 & 326.64 & 503.70 & 761.54 & 648.47 & 588.18 \\
\hline ow8a-89 & $1,037.77$ & $1,418.76$ & $1,443.74$ & 297.95 & 298.90 & 264.82 & 363.80 & 831.25 & 615.36 & 769.96 & $1,038.24$ & 945.25 & 873.77 \\
\hline ow10a-89 & 936.40 & $1,468.98$ & $1,495.94$ & 493.36 & 472.36 & 5.83 & 135.28 & $1,021.28$ & 814.54 & 991.89 & $1,251.22$ & $1,110.40$ & 993.90 \\
\hline ow1d-96 & $1,108.77$ & 887.90 & 901.47 & 543.01 & 557.11 & $1,030.56$ & $1,046.99$ & 11.84 & 221.73 & 180.79 & 250.93 & 168.15 & 323.84 \\
\hline ow2b-96 & $1,051.04$ & 731.25 & 743.17 & 650.67 & 654.79 & $1,116.01$ & $1,114.72$ & 161.78 & 353.22 & 345.41 & 308.64 & 7.12 & 230.90 \\
\hline ow1a-02 & $1,041.67$ & 998.35 & $1,016.53$ & 329.03 & 348.23 & 822.40 & 849.48 & 213.03 & 7.08 & 197.21 & 432.45 & 350.06 & 388.75 \\
\hline ow2a-02 & $1,091.37$ & 728.33 & 738.32 & 701.96 & 707.15 & $1,169.67$ & $1,168.87$ & 194.98 & 398.87 & 368.45 & 287.63 & 59.64 & 271.96 \\
\hline ow3a-02 & $1,214.60$ & $1,059.12$ & $1,073.17$ & 498.33 & 525.65 & 993.65 & $1,031.16$ & 179.28 & 199.69 & 8.54 & 270.05 & 339.88 & 478.21 \\
\hline ow5-02 & 876.54 & 605.30 & 621.96 & 627.28 & 618.47 & $1,046.95$ & $1,026.31$ & 287.08 & 395.93 & 469.67 & 487.07 & 172.44 & 62.85 \\
\hline ow1-08 & $1,369.05$ & $1,033.94$ & $1,041.27$ & 763.46 & 787.12 & $1,259.32$ & $1,289.96$ & 280.23 & 446.77 & 270.81 & 29.17 & 342.41 & 558.86 \\
\hline ow4-09 & 808.94 & 612.63 & 631.97 & 581.10 & 567.84 & 982.57 & 957.31 & 319.30 & 384.77 & 490.64 & 543.12 & 234.99 & 13.21 \\
\hline
\end{tabular}


A

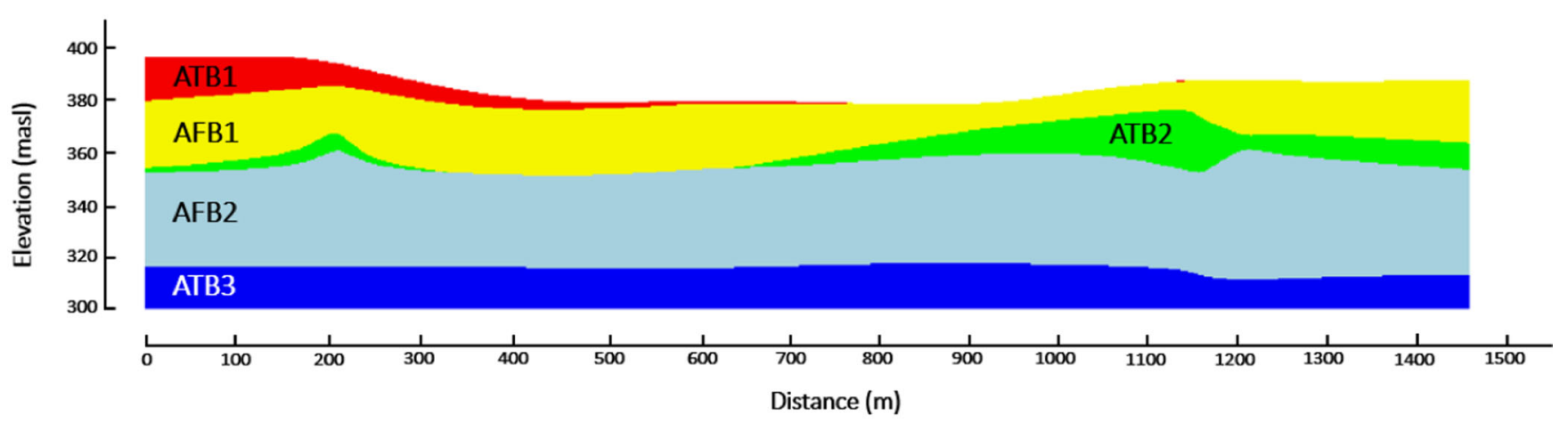

B

$\mathrm{B}^{\prime}$

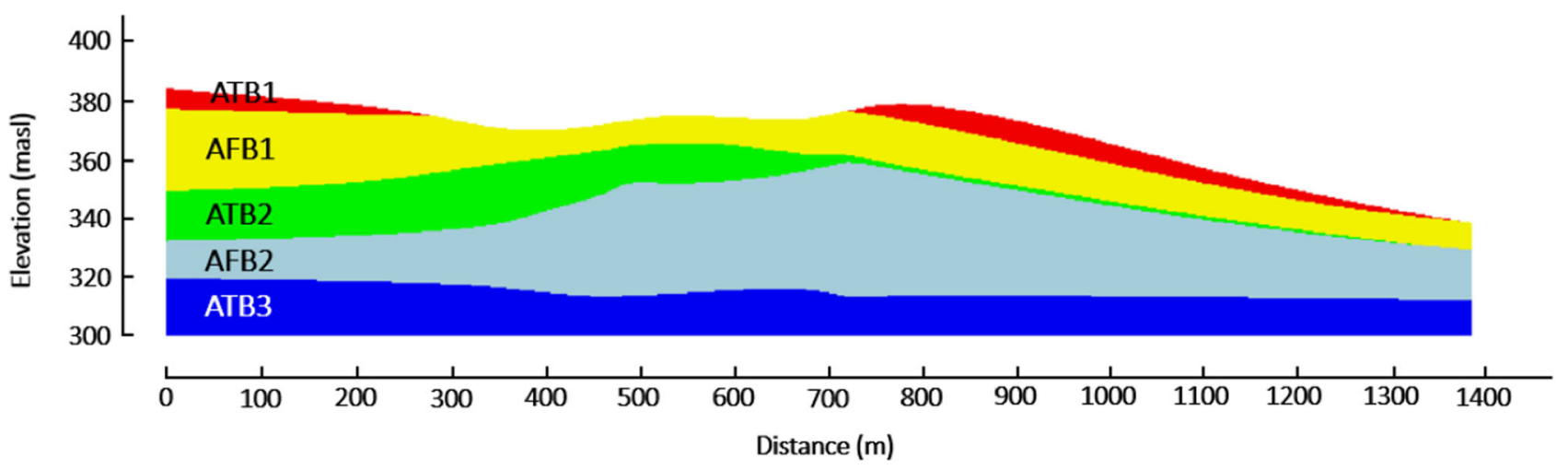

Fig. 2 Cross-sections of the study area (see Fig. 1c), based on the hydrogeological model built with available borehole logs

$\mathrm{A}^{\prime}$ and $\mathrm{B}-\mathrm{B}^{\prime}$ in Fig. 1c). This model only considers the upper portion of the Waterloo Moraine, where the investigated aquifer (AFB2) is located.

The nomenclature of Ontario Geological Survey (OGS) is adopted here for layer identification following the work completed by Bajc and Shirota (2007). In this naming convention, an aquitard is identified with AT followed by a letter and number (e.g., ATB1), whereas an aquifer is identified with AF followed by a letter and number (e.g., AFB1). Following AT or AF, letters and numbers are used to identify the sequence of units, with " $A$ " as the youngest grouped sequence followed by "B" and " 1 " as the youngest unit in group followed by " 2 ". On the basis of previous studies, the geological and hydrogeological units as well as the predominant materials in each unit are summarized in Table 3. Other units identified within the moraine are not included in this study because they are deposited outside the study area.

This study focuses on analyzing the hydraulic properties of the shallow aquifer (AFB2) underlying the Mannheim East Well Field. According to the conceptual hydrogeological model of the Waterloo Moraine built by Bajc and Shirota (2007), AFB2 is mainly recharged from distant outcrops within the moraine. In this study area, ATB1 is a thin and patchy aquitard, while AFB1 is an unconfined aquifer with considerable recharge from precipitation that appears only in the core area of the moraine (Bajc and Shirota 2007). ATB2 is a thin aquitard with low hydraulic conductivity $(K)$ and is known to separate AFB2 and AFB1 in most of the study area. AFB2 is a laterally extensive confined aquifer comprised of mainly of fine sands and some gravels, which results in relatively high $K$. Beneath the AFB2 aquifer, the lower Maryhill Till is designated as ATB3. The $K$ of ATB3 is extremely low, but is continuous across the Mannheim East well field. As a result, AFB2 can be treated as a confined aquifer bounded by ATB2 and ATB3.

\section{Data used for analysis}

A subset pumping/injection rate records from 13 water-supply boreholes (K21, K25, K29, K91, K92, K93, K94, ASR1, ASR2, ASR3, ASR4, RCW1, and RCW2) and water-level records from 14 monitoring boreholes (ow2-09, ow1-10, ow3-85, ow5a-89, ow8a-89, ow10a-89, ow1d-96, ow2b-96, ow1a-02, ow2a-02, ow3a-02, ow5-02, ow1-08, and ow4-09) is obtained from the WRAS+ database (Regional Municipality of Waterloo 2014). Analyses presented in this paper incorporates all of these pumping/injection rates and monitoring data. 
Table 3 Nomenclature of geologic and hydrogeologic units of the upper Waterloo Moraine

\begin{tabular}{|c|c|c|c|c|}
\hline \multirow[t]{2}{*}{ OGS layer name } & \multirow[t]{2}{*}{ Refined hydrostratigraphic unit } & \multicolumn{2}{|l|}{ Interpreted units } & \multirow[t]{2}{*}{ Predominant materials } \\
\hline & & Historical & OGS & \\
\hline ATB1 & Aquitard 1 & $\begin{array}{l}\text { Upper Maryhill Till } \\
\text { Port Stanley Till }\end{array}$ & $\begin{array}{l}\text { Upper Maryhill Till } \\
\text { Port Stanley Till }\end{array}$ & Silty to clayey till \\
\hline AFB1 & Aquifer 1 & Stratified sediments & $\begin{array}{l}\text { Upper Waterloo Moraine stratified } \\
\text { sediments and equivalents }\end{array}$ & Mainly fine sand, some gravel \\
\hline ATB2 & & & Middle Maryhill Till and equivalents & Silty to clayey till, silt, clay \\
\hline AFB2 & & & $\begin{array}{l}\text { Middle Waterloo Moraine stratified } \\
\text { sediments and equivalents }\end{array}$ & Mainly fine sand, some gravel \\
\hline ATB3 & Aquitard 2 & Lower Maryhill Till & Lower Maryhill Till & Silty to clayey till \\
\hline
\end{tabular}

Refined hydrostratigraphic units are defined by Terraqua Investigations Inc. (1995). Ontario Geological Survey (OGS) units are defined by the work completed by Bajc and Shirota (2007)

Pumping/injection rate records in K- and ASR- series boreholes are utilized from January 1, 2005 to December 31, 2013, while records associated with boreholes RCW1 and RCW2 include daily pumping/injection rates from May 1, 2005 to December 31, 2013. These durations are selected based on the continuity and frequency of recorded data in the database. It is important to note that pumping/injection rates in these water supply boreholes are not constant. Instead, they vary frequently in most boreholes. Within the selected period, the daily pumping/injection rate in $\mathrm{K}$ - and ASR- series boreholes varied 3,287 times, while it varied 3,136 times in the RCWseries boreholes.

Water levels are recorded as elevation in the WRAS+ database, and these data are processed to remove barometric effects prior to its inclusion into the database. Selected simulation periods as well as monitoring points associated with each monitoring borehole are summarized in Table S1 of the electronic supplementary material (ESM). Within the selected periods, water levels in monitoring boreholes are continuously recorded every $5 \mathrm{~min}$, and data recorded at the beginning of each day (12:00 am) are extracted and utilized in this study.

The pumping/injection rate records in water-supply boreholes that were utilized in the analysis go back several years prior to the water-level variation data in the monitoring boreholes. Unlike traditional pumping tests, the approach presented here aims to estimate hydraulic properties with existing water-supply pumping and unknown initial heads of groundwater. By including prior pumping records, a value of initial head that represents the static-state water level in the monitoring borehole at the beginning of pumping records (several years prior to the first monitoring point) can be estimated. It should be noted that this estimated value does not reflect real conditions. Instead, it is a value obtained to simulate water-level fluctuations in monitoring boreholes with known pumping/injection records and provides the optimal matching between simulated and monitored water-level data.

\section{Methodology}

The long-term water-supply pumping and water-level records are analyzed with an automatic calibration approach developed by Harp and Vesselinov (2011). In particular, the approach fingerprints transient water-level variations in monitoring boreholes to transient pumping rate changes in individual water-supply boreholes based on a simple analytical model, and hydraulic properties ( $T$ and $S$ ) are estimated through automatic calibration. The simulation of pumping-induced drawdowns in monitoring boreholes is performed using the computer code WELLS (Mishra and Vesselinov 2011), which includes several analytical solutions for confined, leaky-confined, and unconfined aquifers to simulate water-level changes with multiple water-supply boreholes and variable pumping rates. The calibration of WELLS is performed using PEST (Doherty 2005).

The reason for utilizing the WELLS code is that this forward model is suitable for analyzing the responses of multiple water supply boreholes in the study area, in which the pumping/injection rates vary continuously over time. The working principles of WELLS is presented in Harp and Vesselinov (2011). In this study, the Theis (1935) solution (Eq. 1) modified to consider variable pumping/injection rates and multiple water-supply boreholes through the principle of superposition (Eq. 2) is utilized.

$$
\begin{aligned}
& s_{\mathrm{p}}(t)=\frac{Q}{4 \pi T} \mathrm{~W}(u)=\frac{Q}{4 \pi T} \mathrm{~W}\left(\frac{r^{2} S}{4 T t}\right) \\
& s_{\mathrm{p}}(t)=\sum_{i=1}^{N} \sum_{j=1}^{M i} \frac{Q_{i, j}-Q_{i, j-1}}{4 \pi T_{i}} \mathrm{~W}\left[\frac{r_{i}^{2} S_{i}}{4 T_{i}\left(t^{-} t_{Q_{i, j}}\right)}\right]
\end{aligned}
$$

where $s_{\mathrm{p}}(t)$ is the pumping induced drawdown at time $t, N$ is the number of water supply boreholes, $M_{i}$ is the number of pumping records for water-supply borehole $i, Q_{i, j}$ is the pumping rate of the $i$-th borehole during $j$-th pumping record, $r_{i}$ is the distance between the monitoring borehole and $i$-th 
water-supply borehole, and $t_{Q i, j}$ is the time when borehole $i$ changes its pumping rate to the $j$-th pumping period.

ow2-09

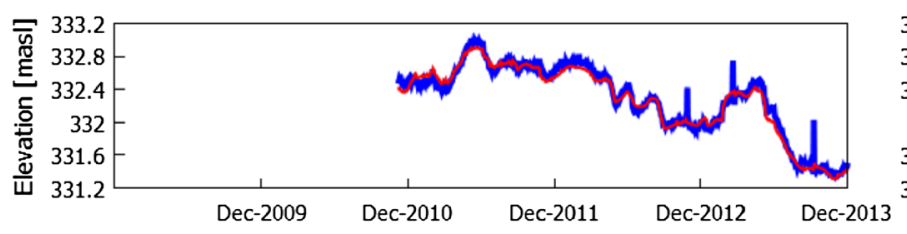

ow3-85

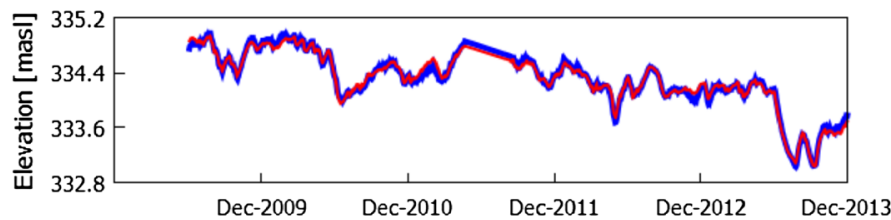

ow8a-89

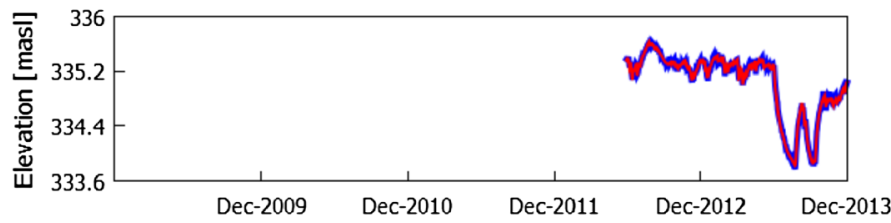

ow1d-96

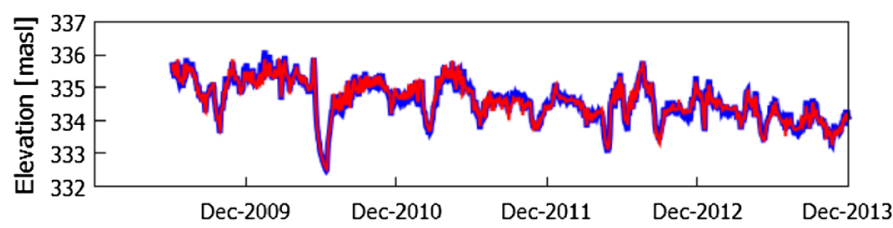

ow1a-02

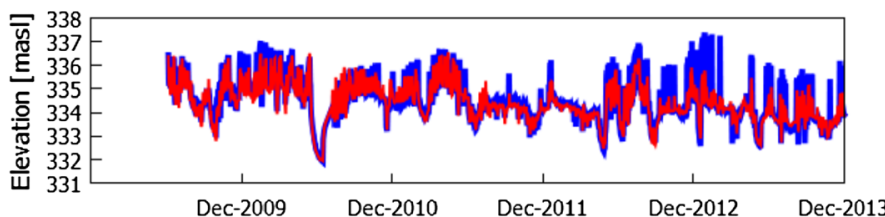

ow3a-02

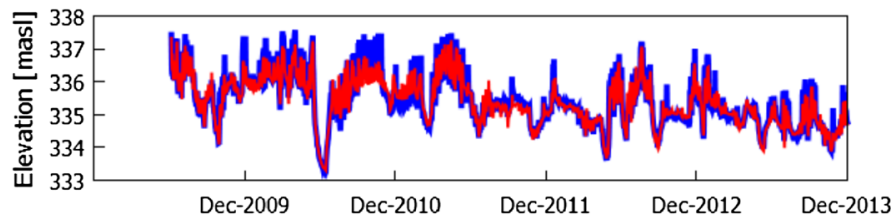

ow1-08

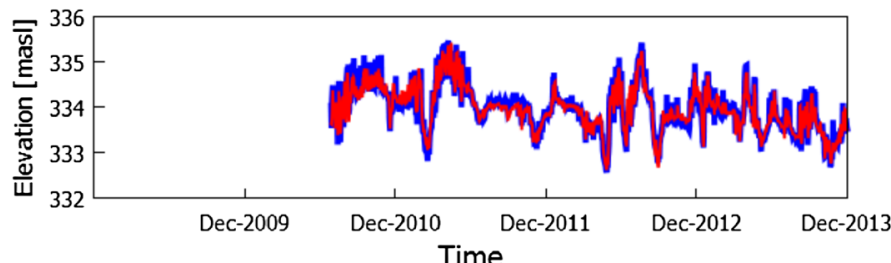

Furthermore, $T_{i}$ and $S_{i}$ refer to the transmissivity and storativity, respectively, associated with pumping influences

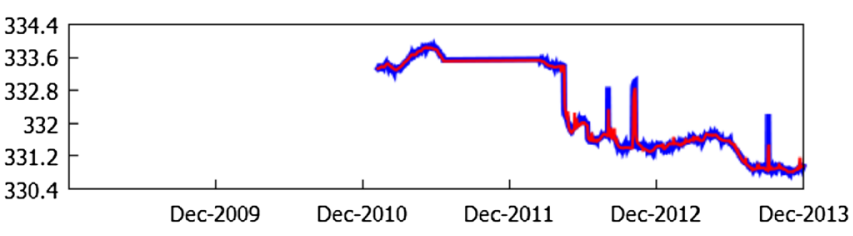

ow5a-89

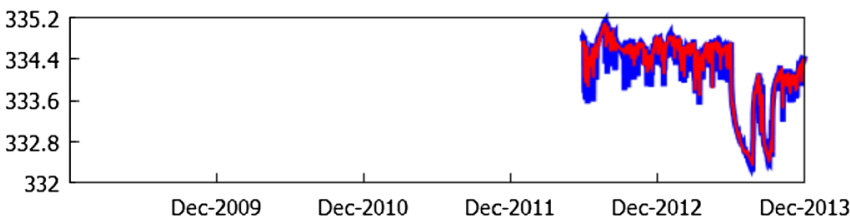

ow10a-89

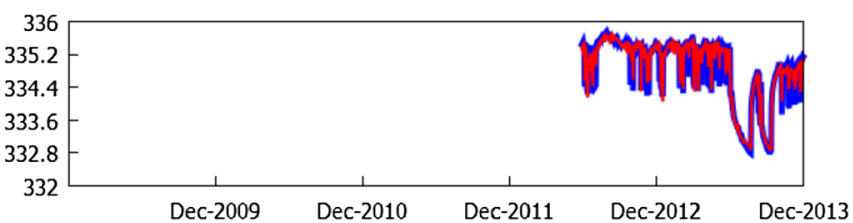

ow2b-96

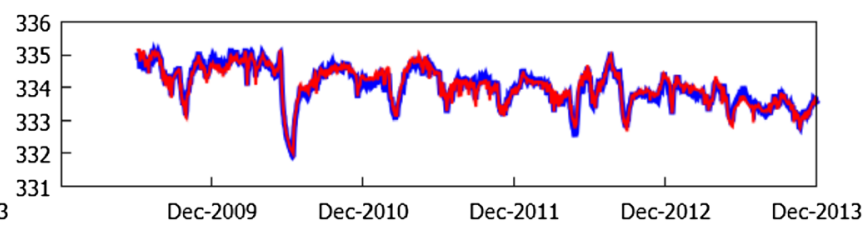

ow2a-02

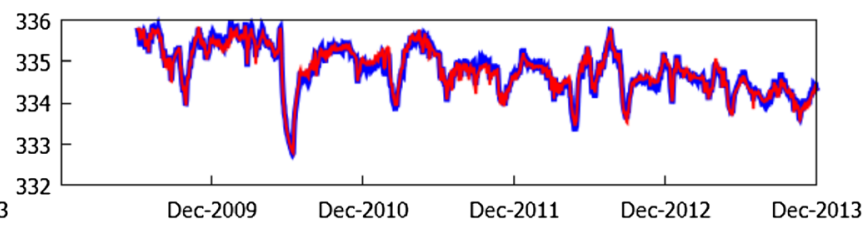

ow5-02

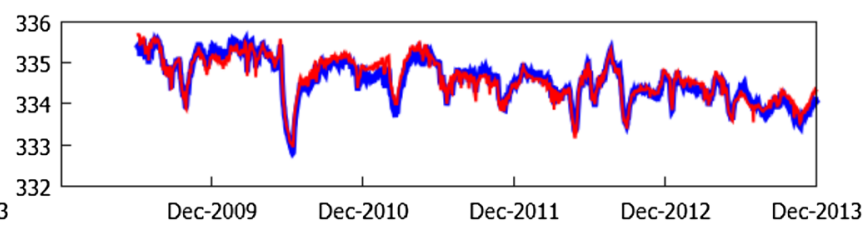

ow4-09

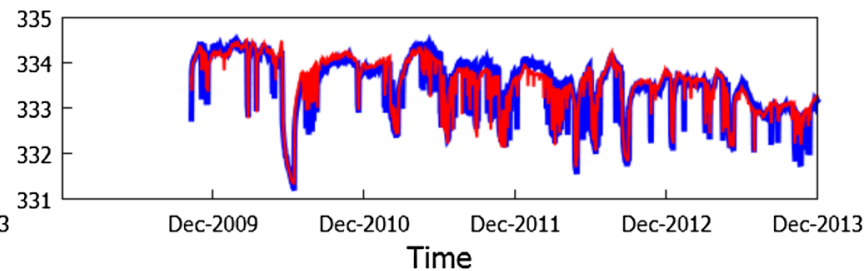

Fig. 3 Matches between monitored and simulated water-level fluctuations in each monitoring borehole. The red curve in each plot shows simulated water levels, while the blue curve indicates monitored water levels 
Fig. 4 Scatterplots of simulated versus monitored drawdowns in monitoring boreholes. The green line is the linear model fit, while the black solid line is the $45^{\circ}$ line

of the $i$-th water-supply borehole on an individual monitoring borehole.

Other than simulating pumping induced drawdowns in monitoring boreholes, an additional drawdown that is not attributed to pumping is identified in the WELLS code. This portion is called the temporal trend of water-level change and calculated using a linear equation:

$s_{\mathrm{t}}(t)=\left(t-t_{0}\right) \times m$

where $s_{\mathrm{t}}(t)$ is the trend drawdown at time $t, t_{0}$ is the time at the beginning of pumping records and $m$ is the linear slope parameter of the temporal trend.

In order to be consistent with the calibration targets of water elevation, the WELLS code calculates the predicted water elevation $[h(t)]$ using:

$h(t)=h_{0}-s_{\mathrm{p}}(t)-s_{\mathrm{t}}(t)$

where $h_{0}$ refers to the predicted water elevation in the monitoring borehole at the beginning of pumping records, instead of the first monitoring point used in simulation. The estimation of $h_{0}$ is achieved by including the pumping records prior to the commencement of water-level records in monitoring boreholes, as described earlier in the section 'Data used for analysis'.

Next, the rationale for utilizing the Theis (1935) solution for the analysis of the dataset is discussed. First, as described previously, the AFB2 aquifer is a nearly confined aquifer that is bounded by extremely low $K$ aquitards ATB 2 and ATB 3 in most of the study area. Although the ATB2 layer is found to be quite thin and hard to identify at some locations, it nevertheless plays an important role in preventing leakage from the overlying unconfined aquifer AFB1. Second, based on the geological logs of the selected 13 water-supply and 14 monitoring boreholes, the thickness of AFB2 ranges from approximately $12 \mathrm{~m}$ in the northeast of the study area to approximately $40 \mathrm{~m}$ in the southwest of the study area. Although the geometry of the aquifer AFB2 does not strictly satisfy the uniform thickness assumption of the Theis (1935) solution, this aquifer is found to be laterally extensive throughout the core area of the Waterloo Moraine with a lower impermeable boundary situated approximately at the same elevation (around 318 masl). Furthermore, the resulting good matches between the simulated and monitored water levels show that the Theis (1935) solution is adequate for the analysis presented in this paper.

The fact that both water-supply and monitoring boreholes partially penetrate the AFB2 aquifer is also considered. In order to examine the impacts of partial penetration on 

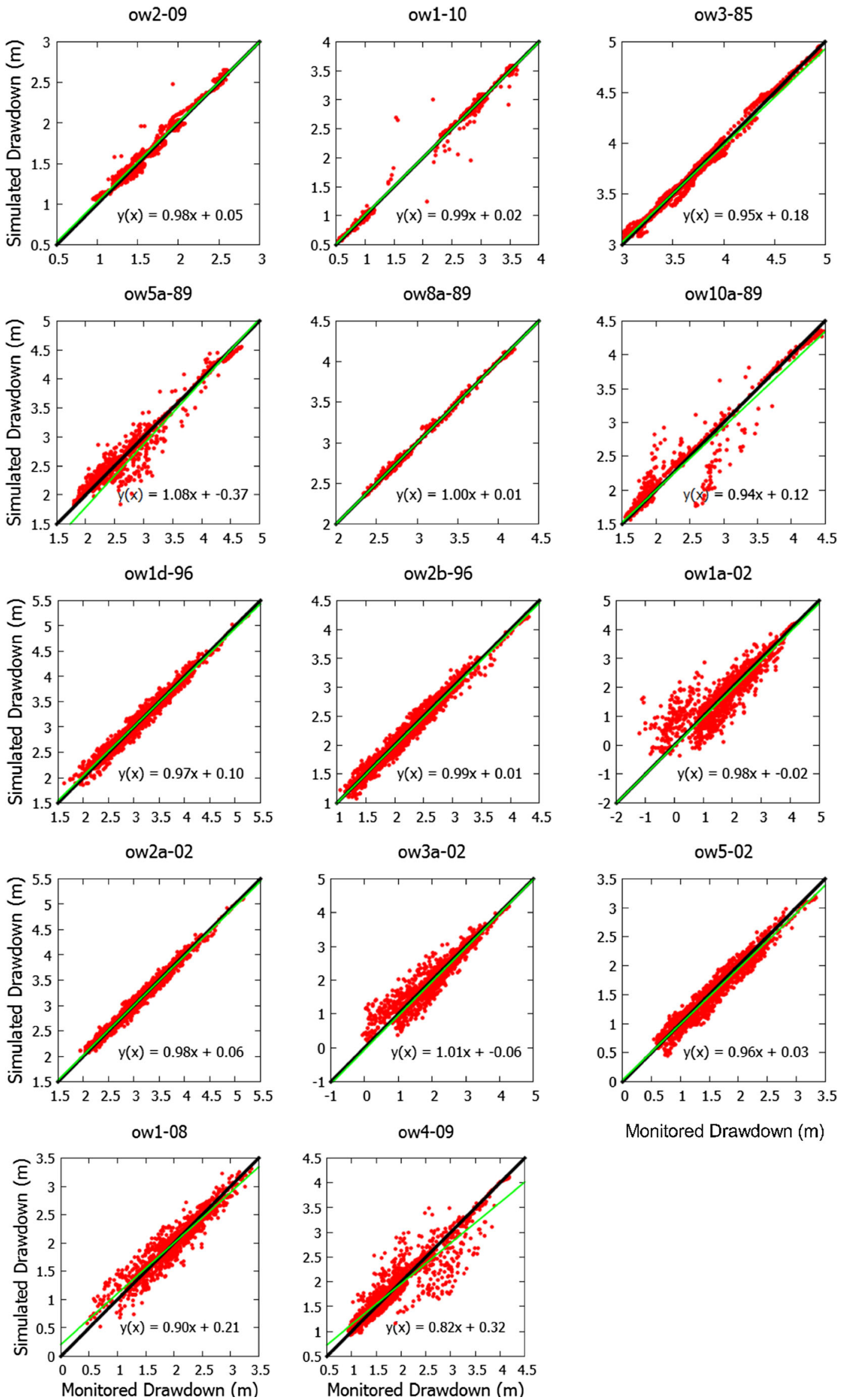

Monitored Drawdown (m) 
drawdowns and whether the Theis (1935) solution could be applied for the analysis of water-level records, the following criterion developed by Hantush (1964) is utilized:

$x=\frac{r}{m} \times \sqrt{\frac{K_{\mathrm{v}}}{K_{\mathrm{h}}}}$

where $r$ is the distance between monitoring and water-supply boreholes [L], $m$ is thickness of the confined aquifer [L], and $K_{\mathrm{v}}$ and $K_{\mathrm{h}}$ represent vertical and horizontal hydraulic conductivities [L/T], respectively. Some assumptions are made in this case to obtain the $x$ values between each monitoring and water supply borehole: (1) the thickness of the AFB2 aquifer is uniform throughout the study area and equals $20 \mathrm{~m}$; (2) the confined aquifer is isotropic with approximately the same $K_{\mathrm{v}}$ and $K_{\mathrm{h}}$ values. Therefore, $x$ values are mainly dependent on the distance between monitoring and water-supply boreholes. According to Hantush (1964), when $x$ is larger than 1.5, the effect of partial well penetration can be neglected and the Theis (1935) solution is applicable. The effect of partial penetration is examined for 182 pairs of water-supply and monitoring boreholes, and the calculated $x$ values are provided in Table $\mathrm{S} 2$ of the ESM Based on this calculation, it can be found that the partial penetration effect can be neglected in most water-supply and monitoring borehole pairs (159 out of 182).

Finally, the Theis (1935) model is the simplest analytical solution, and this minimally parameterized analytical model can be applied to large data sets for a proof-of-concept study. Although utilizing the Theis (1935) solution may fail to result in a good match between simulated and observed drawdowns in some monitoring boreholes, it can still be used to generate information on drawdown responses within the aquifer and verify whether these long-term records are amenable to analysis or not. Furthermore, it should be mentioned that the use of an analytical solution is considered to be the first step in building a more realistic groundwater model using the same data sets. Due to the heterogeneity of the aquifer-aquitard system, a more complete study will have to involve a numerical model that considers the complex geometry of the glacial deposits.

\section{Results and discussion}

\section{Overall simulated results}

In this study, water-level fluctuations at all 14 monitoring boreholes are simulated individually. That is, water-level fluctuation data in each monitoring borehole are calibrated individually by considering pumping/injection rate variations at all water-supply boreholes. Figure 3 shows the match between monitored (blue curves) and simulated (red curves) waterlevel fluctuation data expressed as elevation in each monitoring borehole. Most of the fits are very good to excellent;
Fig. 5 Decomposition results associated with monitoring well ow8a-89. a Water-level elevation and water-supply boreholes K21-K94, b watersupply boreholes ASR1 to RCW2 and temporal trend. In the first plot, the red curve shows simulated water-level elevation, while the blue curve indicates monitored water levels. In the pressure decomposition plots (K21 to RCW2), green curves show pumping or injection rates in watersupply boreholes, while red curves indicate corresponding drawdown contributions from associated water-supply boreholes. The last plot shows the temporal trend of water-level change over time

however, the rapid changes of water level in some monitoring boreholes (e.g. ow5a-89, ow10a-89, ow1a-02, ow3a-02, ow108, and ow4-09) are not fully captured by the model. As illustrated in Fig. 1c, these boreholes are installed close to the water-supply borehole. One reason for the failure in capturing the rapid changes in water levels may be due to the lack of consideration of the partial penetration effect by the Theis (1935) solution, although this does not apply to all monitoring boreholes (e.g., ow1d-96 and ow2b-96). Another more likely reason may be the presence of high $K$ pathways between monitoring boreholes (ow5a-89, ow10a-89, ow1a-02, ow3a02, ow1-08, and ow4-09) and water-supply boreholes (K91, K93, ASR2, ASR3, ASR4, and RCW2); however, with the use of the Theis (1935) solution for the first-cut analysis, the cause of discrepancies between the simulated and monitored water-level variations is not investigated more completely at this time.

In order to assess the simulated results, drawdown values are obtained on the basis of estimated $h_{0}$. Then, the mean absolute error $\left(L_{1}\right)$, mean square error $\left(L_{2}\right)$, as well as the correlation coefficient $(R)$ are computed to quantitatively analyze the discrepancy and correspondence between the simulated and monitored drawdowns. These quantities are computed as:

$$
\begin{aligned}
& L_{1}=\frac{1}{n} \sum_{l=1}^{n}\left|s_{l}-\hat{s}_{l}\right| \\
& L_{2}=\frac{1}{n} \sum_{l=1}^{n}\left(s_{l}-\hat{s}_{l}\right)^{2} \\
& R=\frac{\frac{1}{n} \sum_{l=1}^{n}\left(s_{l}-\mu_{s}\right)\left(\hat{s}_{l}-\mu_{\hat{s}}\right)}{\sqrt{\frac{1}{n} \sum_{l=1}^{n}\left(s_{l}-\mu_{s}\right)^{2} \frac{1}{n} \sum_{l=1}^{n}\left(\hat{s}_{l}-\mu_{\hat{s}}\right)^{2}}}
\end{aligned}
$$

where $n$ is total number of monitoring points, $s_{l}$ and $\hat{s}_{l}$ indicate $l$-th simulated and monitored drawdowns, respectively, while $\mu_{s}$ and $\mu_{\hat{s}}$ are mean values of simulated and monitored drawdowns, respectively. Table 4 summarizes the $L_{1}, L_{2}$, and $R$ values corresponding to each monitoring borehole. The results show that all analyzed monitoring data have a high correspondence between simulated and monitored drawdowns, while relatively large $L_{1}$ and $L_{2}$ values and small $R$ values are calculated at boreholes where rapid 
(a)
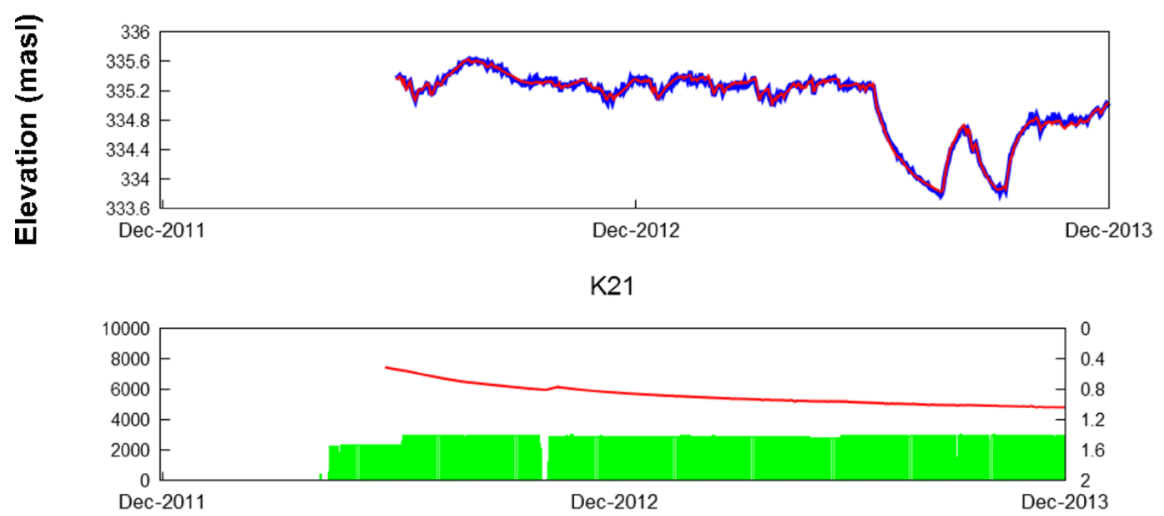

K25

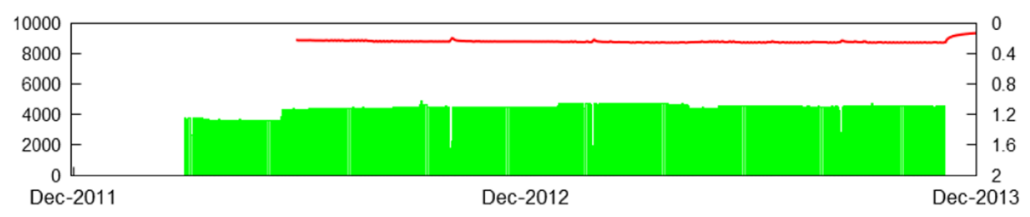

K29
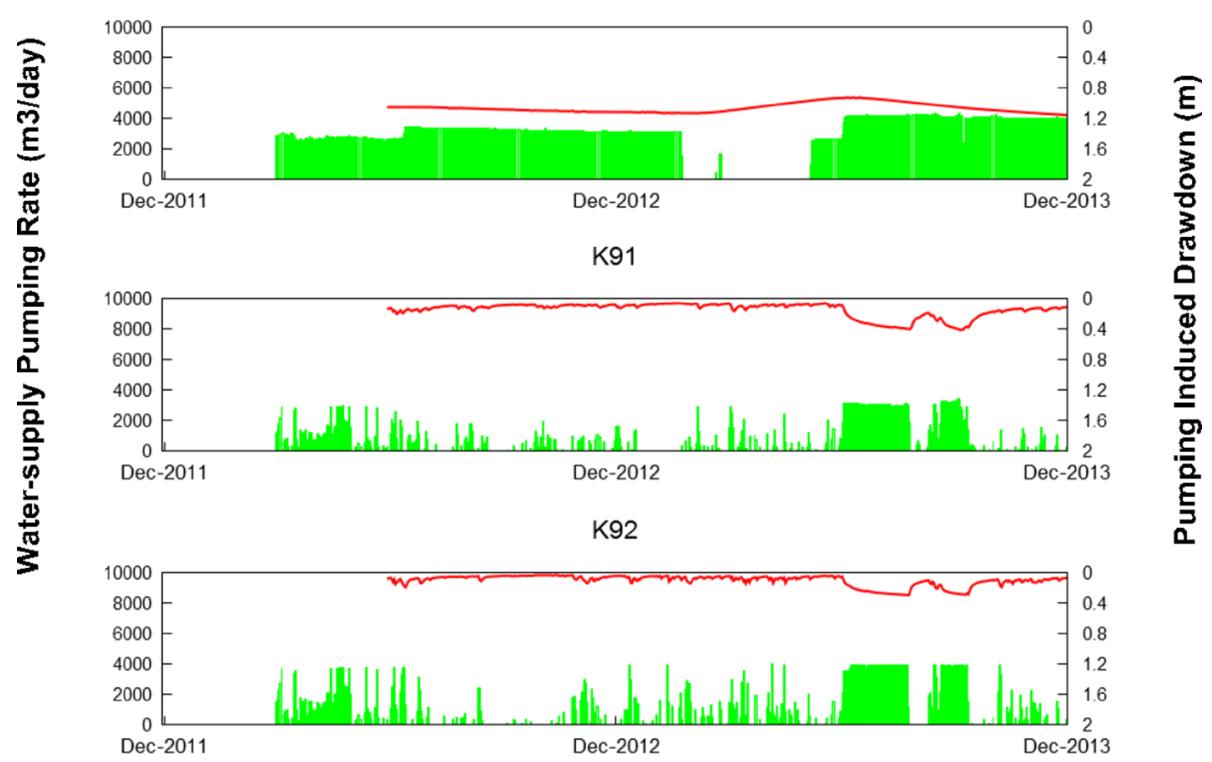

K93

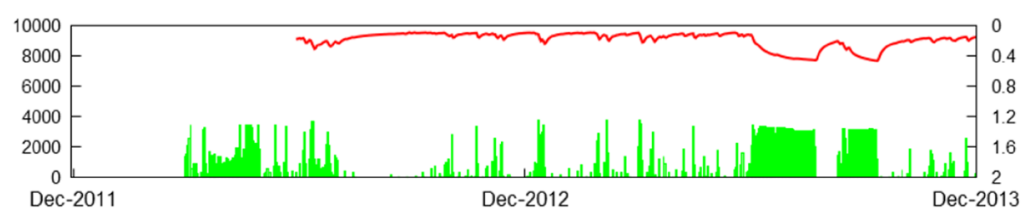

K94

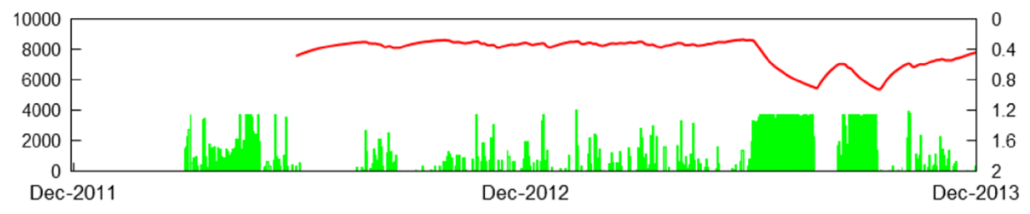

Time 
(b)
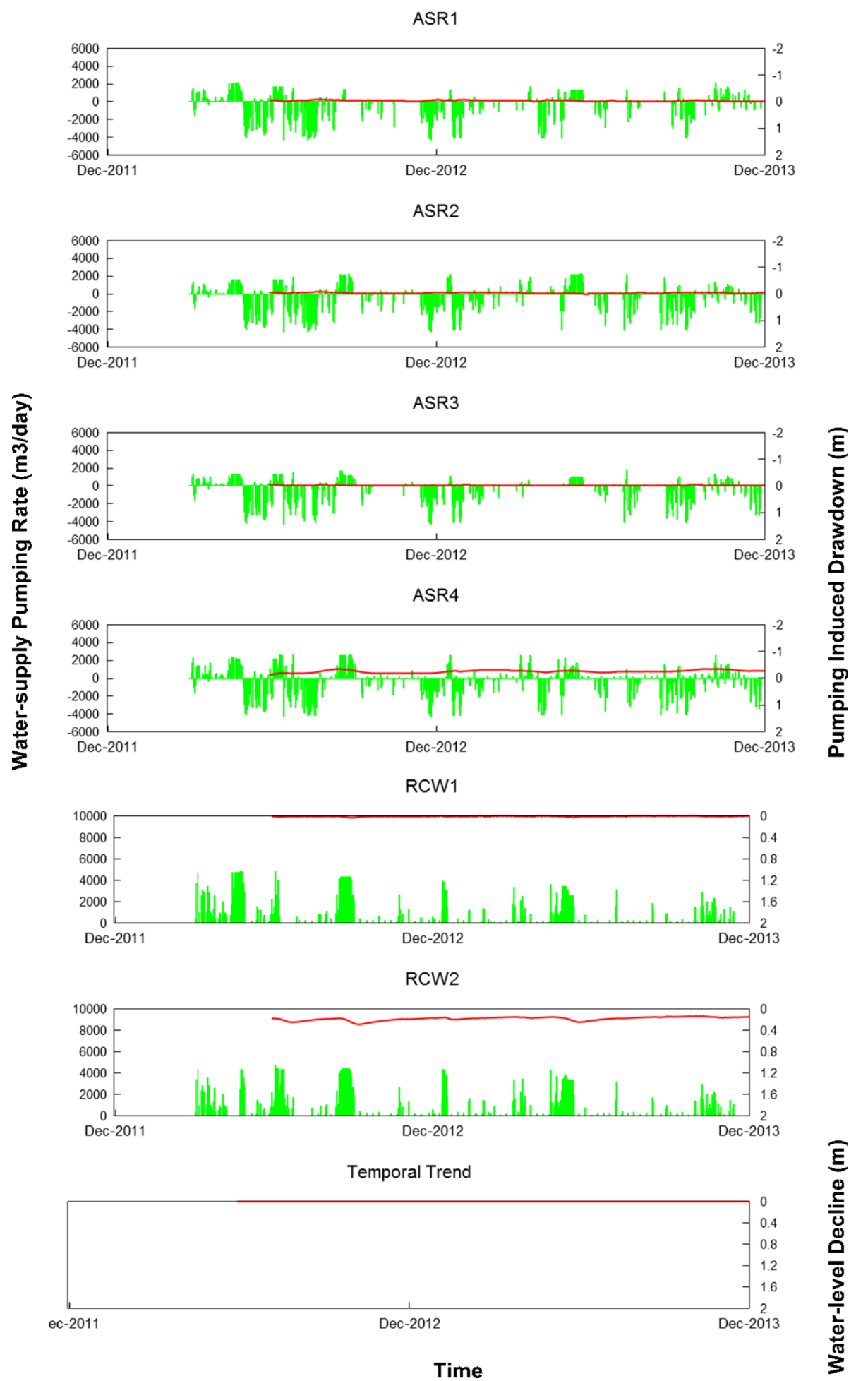

Fig. 5 (continued)

\section{Time}

changes of water level are not fully captured by the Theis (1935) solution.

Furthermore, the scatterplots of simulated versus monitored drawdowns (Fig. 4) are utilized to qualitatively assess the model calibration results. In each plot, pairs of simulated and corresponding monitored drawdowns are expressed as red dots, the black line is the $45^{\circ}$ line, the green line is the fit of the linear model to the data, and the formula of the linear model is 
provided at the bottom of each subplot. The scatterplots provide visual information of the spatial distribution of model calibration errors within the model domain, and they are commonly used to qualitatively evaluate these errors. As shown in Fig. 4, it can be observed that data points are clustered around the $45^{\circ}$ line in all scatterplots, and the trend lines approximately overlap the $45^{\circ}$ line in most plots with the slope of the linear model approximately equal to one with minimal bias. These results indicate that the Theis (1935) solution adequately captures the drawdown behavior at monitoring boreholes when the data are analyzed individually.

\section{Decomposition of pumping influences}

Pumping/injection records from 13 water-supply boreholes are integrated when simulating water fluctuations in each monitoring borehole. The decomposition of pumping/ injection influences is achieved by automatically fitting the superposition of contribution drawdown from each watersupply borehole to monitored drawdowns. Figure 5 shows the decomposition of pumping/injection influences in monitoring borehole ow $8 \mathrm{a}-89$, while the decomposition results for the other 13 monitoring boreholes are provided in Figs. S1S13 of the ESM. Each of these figures consists of 15 subplots: (1) the top plot illustrates the simulated and monitored water levels in each monitoring borehole; (2) the next 13 plots are the simulated drawdown contributions (red curves) from individual water-supply boreholes, as well as their associated pumping/injection records (green curves) (for ASR-series boreholes, negative pumping rates indicates injection, while negative drawdown values indicate water level rise), and (3) the bottom plot is the temporal trend of hydraulic head in each monitoring location identified by the WELLS code.

Examination of Fig. 5 reveals that water-level fluctuation in each monitoring borehole is found to be dominated by the pumping regimes of water-supply boreholes that are installed within the same subdivided well site [e.g. the water level in ow8a-89 (Fig. 5) is mainly controlled by the K90-series boreholes installed within the Peaking well site]. The contribution drawdowns from water-supply boreholes outside of the subdivided well site are commonly small in magnitude and not very sensitive to the corresponding pumping/injection rate changes. These results indicate that pressure propagation may be compartmentalized within the three subdivided well sites. The decomposition of pumping/injection influences in monitoring boreholes provides fundamental insights to how pressure responses travel through the confined aquifer. However, additional studies such as confirmation drilling and inverse modeling of the same dataset with a numerical groundwater model that realistically considers the complexities of the multi-aquifer/aquitard system including their heterogeneity are necessary to substantiate this finding.

\section{Estimated hydraulic properties}

The pumping/injection rate variations due to 13 water-supply boreholes are decomposed for each monitoring borehole, and a set of $T$ and $S$ is estimated between each monitoring and water-supply borehole. These estimated $T$ and $S$ values are summarized in Tables 5 and 6, respectively. A dash in these two tables indicates omitted parameters obtained from negligible contribution drawdowns (between -0.01 and $0.01 \mathrm{~m}$ ), which may lead to erroneous determination of hydraulic properties between monitoring and water-supply boreholes. Similar findings were reported in Harp and Vesselinov (2011), and large estimated $T$ and $S$ values (i.e., $T>10^{5} \mathrm{~m}^{2} /$ day and corresponding $S$ values varying from 0.03 to 10 ) obtained via calibration are considered to be unrealistic and not included in Tables 5 and 6 . The remaining $T$ estimates range from 9 to $55,335 \mathrm{~m}^{2} /$ day with a geometric mean of $1,964.99 \mathrm{~m}^{2} /$ day, while $S$ ranges from 0.002 to 0.736 with a geometric mean of 0.081 . The wide range of estimated hydraulic parameters suggests that this aquifer is highly heterogeneous; however, in order to capture this heterogeneity, 3D inverse modeling of water-level fluctuations that treats the aquifer to be heterogeneous is necessary.

Table 7 summarizes the $T$ and $S$ estimates obtained from previous aquifer tests and are compared to the geometric mean values from this study. Although the estimated $T$ and $S$ vary quite widely in most water-supply boreholes, their geometric means are within the same order of magnitude and similar to those obtained from previous aquifer tests (Trow Dames \& Moore 1990; CH2MILL and Papadopulos Associates 2003; CH2M HILL 2003).

The estimation of $T$ and $S$ in this study is achieved by fingerprinting transient water-level variations in monitoring boreholes to transient pumping/injection rate changes in water-supply boreholes, and they are conceptually similar to parameters that are obtained from dedicated pumping tests using the Theis (1935) solution (Harp and Vesselinov 2011). Basically, these hydraulic parameters can be used to characterize the water-level variations at a monitoring location when operating a water-supply borehole; however, they cannot be considered as accurate estimates due to the limitation of the assumptions implied in the Theis (1935) solution. Instead, Harp and Vesselinov (2011) consider such estimates as interpreted hydraulic parameters (Sanchez-Vila et al. 2006) and point out that these parameters should not be confused with effective or equivalent parameters.

\section{Validation of $T$ and $S$ estimates}

Next, the estimated hydraulic properties from each watersupply and monitoring borehole pair are validated through predictions of drawdowns in nearby monitoring boreholes. In particular, 13 pairs of $T$ and $S$ estimates from ow8a-89 as 
Table 5 Transmissivity $(T)$ estimated between each pair of monitoring and water-supply boreholes $\left[\mathrm{m}^{2} /\right.$ day]

Water- Monitoring boreholes

supply

boreholes ow1-08 ow2a-02 ow2b-96 ow1d-96 ow3a-02 ow5-02 ow4-09 ow1a-02 ow3-85 ow5-89 ow8-89 ow10-89 ow2-09 ow1-10

\begin{tabular}{lllllllllllllll}
\hline K21 & 646 & 655 & 571 & 612 & 918 & 1,563 & 789 & 1,786 & 525 & 2,084 & 887 & 991 & 587 & 1,016 \\
K25 & 24,044 & 601 & 2,173 & 536 & 1,589 & 4,345 & 12,445 & 989 & 689 & 9,550 & 8,610 & 4,416 & 55,335 & 8,974 \\
K29 & 818 & 800 & 5,224 & 959 & 897 & 4,581 & 3,673 & 6,266 & 670 & 486 & 461 & 530 & - & 643 \\
K91 & 2,186 & 9,078 & 9,594 & 15,704 & 11,429 & 7,656 & 12,764 & 5,508 & 644 & 2,046 & 1,742 & 3,357 & 350 & 133 \\
K92 & 7,780 & 7,178 & 9,528 & 8,954 & 9,057 & 8,279 & 5,129 & 10,740 & 3,243 & 2,193 & 3,936 & 533 & 4,121 & 1,178 \\
K93 & 2,218 & 2,099 & 3,048 & 1,384 & 966 & 3,690 & 4,236 & 1,321 & 982 & 1,986 & 1,832 & 2,415 & 2,280 & 1,614 \\
K94 & 630 & 993 & 1,023 & 1,047 & 1,435 & 2,173 & 1,074 & 456 & 9,727 & 624 & 618 & 1,936 & 1,589 & 1,052 \\
ASR1 & 5,470 & 2,443 & 2,716 & 4,955 & 966 & 2,489 & 2,685 & 3,236 & - & 2,339 & 2,972 & 4,416 & 5,284 & 889 \\
ASR2 & 2,618 & 11,041 & 8,610 & 5,483 & 4,256 & 4,581 & - & 1,652 & - & 5,070 & 3,733 & 1,069 & - & 667 \\
ASR3 & 716 & 34,834 & 11,324 & 28,510 & 2,655 & 14,997 & - & - & - & 4,130 & 5,572 & 692 & 6,622 & 226 \\
ASR4 & 948 & 495 & 474 & 501 & 873 & 476 & 689 & 861 & 524 & 540 & 234 & 87 & 281 & 9 \\
RCW1 & 968 & 1,581 & 5,272 & 1,140 & 1,854 & 1,340 & 2,404 & 1,535 & 450 & 1,556 & 16,069 & 484 & 2,339 & 5,984 \\
RCW2 & 5,082 & 1,374 & 986 & 1,633 & 1,535 & 13,366 & 2,148 & 2,382 & 3,428 & 3,365 & 1,109 & 820 & 5,495 & 3,673 \\
\hline
\end{tabular}

Dash indicates omitted $T$ values

well as their geometric mean are utilized individually for forward simulations of water-level fluctuations in monitoring boreholes ow3-85, ow5a-89, and ow10a-89 at the Peaking well site. In each forward simulation, 13 water-supply boreholes and the same pumping/injection records from the calibration effort are utilized. Due to the lack of information of initial heads in monitoring boreholes, water-level variation instead of water elevation is used for comparison purposes. In this case, the first simulated or monitored water-level data is applied as the datum point, and water-level variations are computed as the differences between this datum value and the simulated or monitored water-level data.
Figure 6 shows the scatterplots of simulated and monitored water-level variations in monitoring borehole ow5a-89, while the forward simulation results associated with the other two boreholes (ow3-85 and ow10a-89) are provided in Figs. S14 and S15 of the ESM. Each plot in these figures corresponds to the use of a set of $T$ and $S$ estimated from borehole ow8a-89 and the corresponding water-supply boreholes are labeled on the top of each plot. On the basis of these results, it can be observed that water-level variations in nearby monitoring boreholes are poorly simulated when utilizing most individual $T$ and $S$ estimates obtained from borehole ow8a-89. This suggests that $T$ and $S$ estimates from individual pumping and

Table 6 Storativity $(S)$ estimated between each pair of monitoring and water-supply boreholes [-]

\begin{tabular}{|c|c|c|c|c|c|c|c|c|c|c|c|c|c|c|}
\hline \multirow{2}{*}{$\begin{array}{l}\text { Water- } \\
\text { supply } \\
\text { boreholes }\end{array}$} & \multicolumn{14}{|c|}{ Monitoring boreholes } \\
\hline & ow1-08 & ow2a-02 & ow2b-96 & ow1d-96 & ow3a-02 & ow5-02 & ow4-09 & ow1a-02 & ow3-85 & ow5-89 & ow8-89 & ow10-89 & ow2-09 & ow1-10 \\
\hline K21 & 0.086 & 0.017 & 0.144 & 0.122 & 0.135 & 0.194 & 0.394 & 0.137 & 0.361 & 0.032 & 0.042 & 0.069 & 0.067 & 0.042 \\
\hline K25 & 0.078 & 0.206 & 0.232 & 0.135 & 0.282 & 0.040 & 0.077 & 0.194 & 0.150 & 0.040 & 0.006 & 0.068 & 0.136 & 0.037 \\
\hline K29 & 0.092 & 0.272 & 0.048 & 0.203 & 0.233 & 0.017 & 0.089 & 0.076 & 0.100 & 0.120 & 0.074 & 0.058 & - & 0.065 \\
\hline K91 & 0.512 & 0.101 & 0.058 & 0.075 & 0.042 & 0.046 & 0.092 & 0.028 & 0.121 & 0.028 & 0.059 & 0.467 & 0.100 & 0.191 \\
\hline K92 & 0.194 & 0.143 & 0.078 & 0.119 & 0.074 & 0.058 & 0.060 & 0.038 & 0.321 & 0.046 & 0.038 & 0.061 & 0.221 & 0.166 \\
\hline K93 & 0.051 & 0.084 & 0.104 & 0.050 & 0.052 & 0.069 & 0.366 & 0.050 & 0.065 & 0.155 & 0.085 & 0.002 & 0.132 & 0.206 \\
\hline K94 & 0.066 & 0.042 & 0.084 & 0.059 & 0.082 & 0.094 & 0.028 & 0.153 & 0.520 & 0.059 & 0.105 & 0.043 & 0.108 & 0.077 \\
\hline ASR1 & 0.119 & 0.047 & 0.058 & 0.026 & 0.128 & 0.047 & 0.083 & 0.036 & - & 0.078 & 0.096 & 0.119 & 0.273 & 0.020 \\
\hline ASR2 & 0.736 & 0.082 & 0.124 & 0.042 & 0.036 & 0.074 & - & 0.009 & - & 0.211 & 0.289 & 0.094 & - & 0.072 \\
\hline ASR3 & 0.357 & 0.064 & 0.075 & 0.036 & 0.007 & 0.066 & - & - & - & 0.239 & 0.257 & 0.160 & 0.426 & 0.042 \\
\hline ASR4 & 0.282 & 0.079 & 0.065 & 0.087 & 0.121 & 0.038 & 0.042 & 0.033 & 0.043 & 0.068 & 0.042 & 0.026 & 0.040 & 0.022 \\
\hline RCW1 & 0.060 & 0.179 & 0.017 & 0.086 & 0.034 & 0.060 & 0.228 & 0.035 & 0.096 & 0.373 & 0.148 & 0.096 & 0.084 & 0.038 \\
\hline RCW2 & 0.058 & 0.226 & 0.159 & 0.215 & 0.058 & 0.030 & 0.008 & 0.049 & 0.082 & 0.424 & 0.077 & 0.029 & 0.134 & 0.217 \\
\hline
\end{tabular}

Dash indicates omitted $S$ values 
Table 7 Transmissivity $(T)$ and storativity $(S)$ estimates obtained from previous aquifer tests conducted at the Mannheim East Well Field utilizing different analytical solutions, as well as the geometric means of $T$ and $S$ obtained in this study

\begin{tabular}{|c|c|c|c|c|c|c|}
\hline \multirow[t]{2}{*}{ Well site } & \multirow[t]{2}{*}{ Water-supply boreholes } & \multicolumn{3}{|c|}{ Values obtained from previous aquifer tests } & \multicolumn{2}{|c|}{ Geometric means obtained in this study } \\
\hline & & $T$ ( $\mathrm{m}^{2} /$ day $)$ & $S$ & Test method & $T$ ( $\mathrm{m}^{2} /$ day) & $S$ \\
\hline \multirow[t]{3}{*}{ Mannheim East ${ }^{\mathrm{a}}$} & $\mathrm{K} 21$ & $\begin{array}{l}1,373 \\
1,500\end{array}$ & $\begin{array}{l}\text { NA } \\
0.07\end{array}$ & $\begin{array}{l}\text { Cooper and Jacob (1946) } \\
\text { Theis (1935) }\end{array}$ & 882 & 0.093 \\
\hline & $\mathrm{K} 25$ & $\begin{array}{l}6,061 \\
5,200\end{array}$ & $\begin{array}{l}\text { NA } \\
0.064\end{array}$ & $\begin{array}{l}\text { Cooper and Jacob (1946) } \\
\text { Theis (1935) }\end{array}$ & 3,884 & 0.085 \\
\hline & & 8,700 & 0.13 & Distance-drawdown & & \\
\hline \multirow[t]{4}{*}{ Peaking ${ }^{\mathrm{b}}$} & K91 & 1,318 & 0.18 & Distance-drawdown & 3,070 & 0.089 \\
\hline & K92 & 1,976 & 0.07 & Distance-drawdown & 4,507 & 0.092 \\
\hline & K93 & 1,976 & 0.06 & Distance-drawdown & 1,961 & 0.07 \\
\hline & K94 & 1,581 & 0.12 & Distance-drawdown & 1,197 & 0.081 \\
\hline \multirow[t]{10}{*}{$\mathrm{ASR}^{\mathrm{c}}$} & ASR1 & 5,630 & 0.16 & Cooper and Jacob (1946) & 2,761 & 0.069 \\
\hline & ASR2 & $\begin{array}{l}1,090 \\
1,770\end{array}$ & $\begin{array}{l}\mathrm{NA} \\
0.04\end{array}$ & $\begin{array}{l}\text { Cooper and Jacob (1946) } \\
\text { Theis }(1935)\end{array}$ & 3,348 & 0.09 \\
\hline & & 1,200 & 0.2 & Distance-drawdown & & \\
\hline & ASR3 & $\begin{array}{l}3,040 \\
2,180\end{array}$ & $\begin{array}{l}\text { NA } \\
0.04\end{array}$ & $\begin{array}{l}\text { Cooper and Jacob (1946) } \\
\text { Theis (1935) }\end{array}$ & 4,224 & 0.094 \\
\hline & & 1,590 & 0.2 & Distance-drawdown & & \\
\hline & ASR4 & $\begin{array}{l}1,170 \\
5,710\end{array}$ & $\begin{array}{l}\text { NA } \\
0.06\end{array}$ & $\begin{array}{l}\text { Cooper and Jacob (1946) } \\
\text { Theis (1935) }\end{array}$ & 349 & 0.055 \\
\hline & & 1,280 & 0.22 & Distance-drawdown & & \\
\hline & RCW1 & $\begin{array}{l}3,230 \\
2,890\end{array}$ & $\begin{array}{l}\text { NA } \\
0.006\end{array}$ & $\begin{array}{l}\text { Cooper and Jacob (1946) } \\
\text { Neuman (1974) }\end{array}$ & 1,871 & 0.080 \\
\hline & & 3,000 & 0.2 & Distance-drawdown & & \\
\hline & RCW2 & $\begin{array}{l}2,900 \\
1,140\end{array}$ & $\begin{array}{l}\text { NA } \\
0.09\end{array}$ & $\begin{array}{l}\text { Cooper and Jacob (1946) } \\
\text { Distance-drawdown }\end{array}$ & 2,430 & 0.083 \\
\hline
\end{tabular}

${ }^{\mathrm{a}} \mathrm{CH} 2 \mathrm{M}$ HILL and Papadopulos Associates 2003

${ }^{\mathrm{b}}$ Trow Dames \& Moore 1990

${ }^{\mathrm{c}} \mathrm{CH} 2 \mathrm{M}$ HILL 2003

monitoring boreholes when the aquifer is treated to be uniform may not be the best estimate to predict drawdowns at other locations (e.g., Wu et al. 2005; Berg and Illman 2015).

Also, the mean absolute error $\left(L_{1}\right)$, mean square error $\left(L_{2}\right)$, and correlation coefficient $(R)$ are computed here to quantitatively assess forward simulation results utilizing Eqs. (6)-(8). Table 8 summarizes the $L_{1}, L_{2}$, and $R$ values, and their corresponding arithmetic means of $L_{1}$ and $L_{2}$. The results reveal that the $R$ value is relatively high and does not vary significantly, while the $L_{1}$ and $L_{2}$ values vary quite widely. Relatively small $L_{1}$ and $L_{2}$ values are in italic in Table 8, implying low discrepancy between simulated and monitored water-level variations. These forward simulation results indicate that "selected" $T$ and $S$ estimates may better represent hydraulic properties of the aquifer; however, it has to be kept in mind that one does not know a priori which $T$ and $S$ estimates would be most robust in predicting other drawdown inducing events. This is in line with the conclusion reached by $\mathrm{Wu}$ et al. (2005) and Berg and Illman (2015) who both have shown that traditional pumping tests that treat the aquifer to be homogeneous generally yield biased hydraulic parameters that cannot be used in accurately predicting drawdowns from other pumping tests. This is because homogeneous $T$ and $S$ estimates obtained from analytical solutions are only representative of the aquifer between the pumping and monitoring boreholes as pointed out by $\mathrm{Wu}$ et al. (2005); hence, drawdown data from multiple boreholes and aquifer stressing events need to be jointly interpreted using a suitable inverse model that considers the medium to be heterogeneous.

\section{Trend decline of water level}

Beyond the decomposition of pumping/injection influences and estimation of hydraulic properties, a trend decline in the water level not attributed to the influence of pumping/ injection is also identified by the WELLS. The results indicate that a relatively significant decline in water level is identified at boreholes ow2b-96 (0.164 m/year), owla-02 (0.055 m/year), ow3a-02 (0.149 m/year), ow5-02 (0.159 m/year), ow1-08 (0.085 m/year), ow4-09 (0.191 m/year), and ow1-10 (0.071 
Fig. 6 Scatterplots of simulated versus monitored water-level variations in monitoring borehole ow5a-89 when utilizing the $T$ and $S$ estimates from borehole ow8a-89 for forward simulation. The green line is the linear model fit, while the black solid line is the $45^{\circ}$ line
ASR1

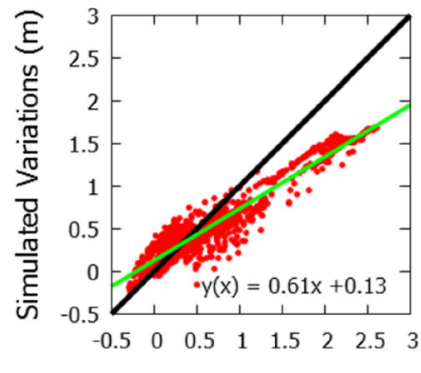

ASR4

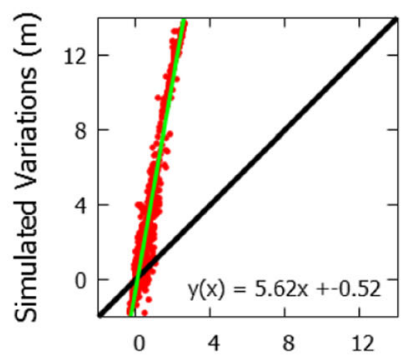

K29

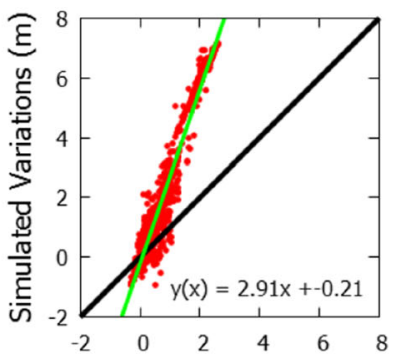

K93

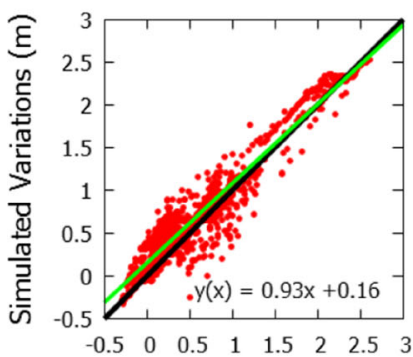

RCW2

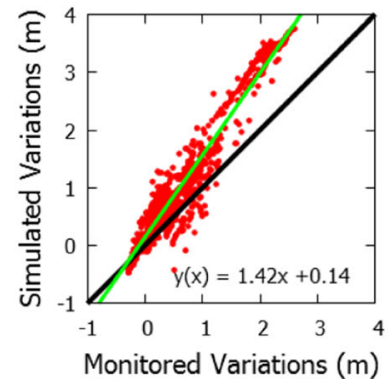

ASR2

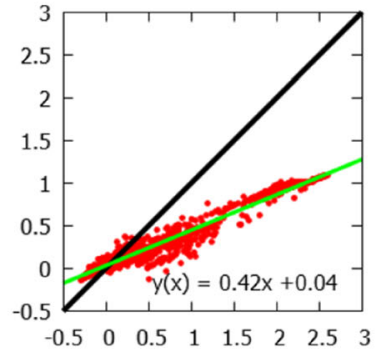

K21

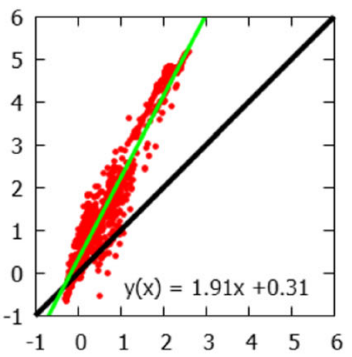

K91

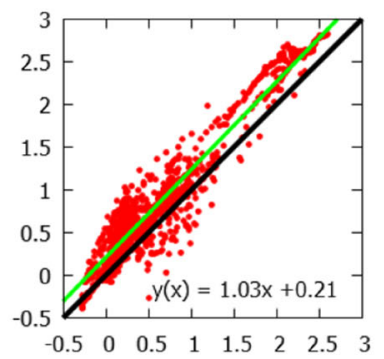

K94

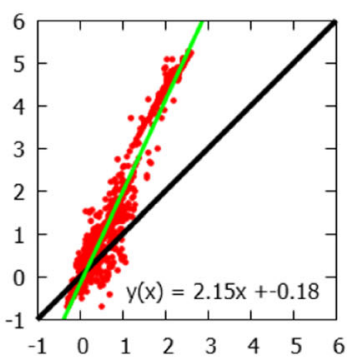

GEOMETRIC

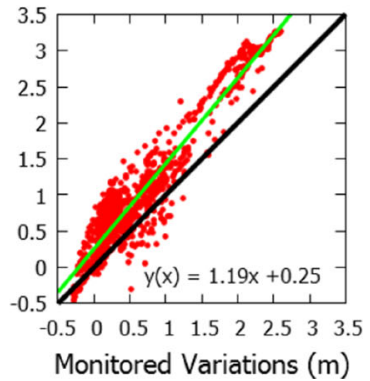

ASR3

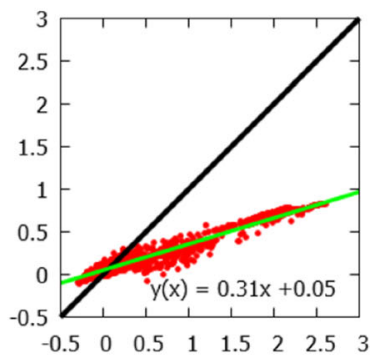

K25

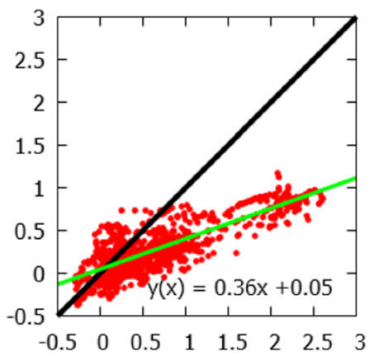

K92

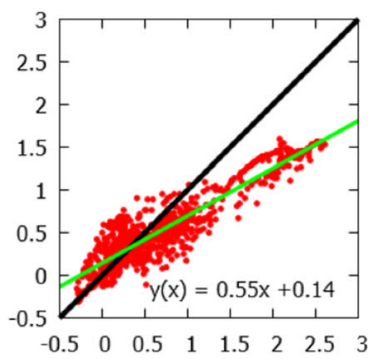

RCW1

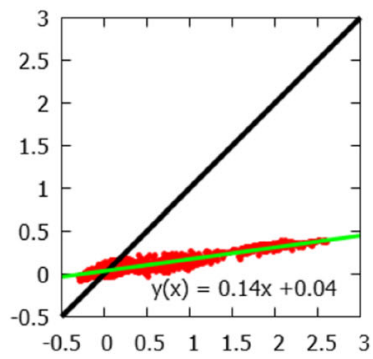

Monitored Variations (m) 
Table 8 The mean absolute error $\left(L_{1}\right)$, mean square error $\left(L_{2}\right)$, and correlation coefficient $(R)$ between simulated and monitored water-level variations in three nearby monitoring boreholes when utilizing each $T$ and $S$ set and their geometric means obtained from borehole ow 8 a- 89

\begin{tabular}{|c|c|c|c|c|c|c|c|c|c|c|c|c|c|c|}
\hline \multirow[t]{2}{*}{ Statistic } & \multicolumn{13}{|c|}{ Water-supply boreholes } & \multirow[t]{2}{*}{ Geometric mean } \\
\hline & K21 & K25 & K29 & K91 & K92 & K93 & K94 & ASR1 & ASR2 & ASR3 & ASR4 & RCW1 & RCW2 & \\
\hline \multicolumn{15}{|c|}{ Monitoring borehole ow3-85 } \\
\hline$L_{1}$ & 0.823 & 0.264 & 0.676 & 0.323 & 0.223 & 0.195 & 0.371 & 0.165 & 0.274 & 0.300 & 1.606 & 0.363 & 0.371 & 0.220 \\
\hline$L_{2}$ & 0.876 & 0.112 & 0.779 & 0.139 & 0.079 & 0.056 & 0.232 & 0.043 & 0.118 & 0.147 & 4.564 & 0.218 & 0.177 & 0.072 \\
\hline$R$ & 0.916 & 0.610 & 0.963 & 0.895 & 0.797 & 0.916 & 0.963 & 0.893 & 0.947 & 0.920 & 0.962 & 0.806 & 0.939 & 0.897 \\
\hline \multicolumn{15}{|c|}{ Monitoring borehole ow5a-89 } \\
\hline$L_{1}$ & 0.896 & 0.411 & 1.100 & 0.265 & 0.272 & 0.174 & 0.657 & 0.237 & 0.350 & 0.403 & 2.575 & 0.518 & 0.437 & 0.184 \\
\hline$L_{2}$ & 1.305 & 0.348 & 2.946 & 0.100 & 0.138 & 0.049 & 1.055 & 0.104 & 0.276 & 0.376 & 16.611 & 0.603 & 0.316 & 0.054 \\
\hline$R$ & 0.961 & 0.832 & 0.97 & 0.955 & 0.922 & 0.961 & 0.970 & 0.954 & 0.967 & 0.961 & 0.970 & 0.921 & 0.966 & 0.956 \\
\hline \multicolumn{15}{|c|}{ Monitoring borehole ow10a-89 } \\
\hline$L_{1}$ & 0.744 & 0.423 & 1.084 & 0.261 & 0.342 & 0.202 & 0.675 & 0.294 & 0.373 & 0.423 & 2.557 & 0.507 & 0.362 & 0.224 \\
\hline$L_{2}$ & 1.000 & 0.387 & 2.772 & 0.095 & 0.193 & 0.067 & 0.992 & 0.167 & 0.357 & 0.462 & 16.259 & 0.676 & 0.233 & 0.075 \\
\hline$R$ & 0.953 & 0.857 & 0.953 & 0.951 & 0.933 & 0.953 & 0.953 & 0.950 & 0.954 & 0.953 & 0.953 & 0.932 & 0.954 & 0.951 \\
\hline \multicolumn{15}{|c|}{ Arithmetic mean } \\
\hline$L_{1}$ & 0.834 & 0.342 & 0.894 & 0.292 & 0.261 & 0.189 & 0.523 & 0.212 & 0.317 & 0.357 & 2.106 & 0.442 & 0.393 & 0.208 \\
\hline$L_{2}$ & 1.046 & 0.241 & 1.874 & 0.118 & 0.119 & 0.056 & 0.649 & 0.086 & 0.214 & 0.281 & 10.750 & 0.431 & 0.235 & 0.066 \\
\hline$R$ & 0.943 & 0.766 & 0.962 & 0.934 & 0.884 & 0.943 & 0.962 & 0.932 & 0.956 & 0.945 & 0.962 & 0.886 & 0.963 & 0.934 \\
\hline
\end{tabular}

The arithmetic means of $L_{1}$ and $L_{2}$ associated with each $T$ and $S$ set are listed at the bottom. Italicized numbers highlight the relatively low $L_{1}$ and $L_{2}$ values $\left(L_{1}<0.25\right.$ and $\left.L_{2}<0.1\right)$

$\mathrm{m} / \mathrm{year}$ ) during the simulated periods. Most of these boreholes are constructed at the ASR well site, while only one monitoring borehole (ow1-10) is located to the north of the Mannheim East well site. The distribution of the identified trend decline is found to be irregular instead of concentrated in a certain area. This trend decline might be caused by several sources such as: (1) reduced local recharge, (2) additional operating water supply boreholes, or (3) other drawdown-inducing activities in the study area. In particular, the trend decline of water level at the ASR well site may be attributed to additional drawdown caused by nearby sources of groundwater withdrawals. In fact, a quarry is located approximately $300 \mathrm{~m}$ south to the ASR well site. At the present moment, the effects of this quarry on the water levels in the study area are unknown and need to be studied further.

Overall, the analysis presented in this paper reveals that long-term pumping and water-level variation records at the Mannheim East site are amenable to analyses with the Theis (1935) solution. At a municipal well field, pumping/injection rates of numerous water-supply/recharge boreholes can fluctuate significantly over the operational period. Therefore, variable pumping/injection rates of multiple boreholes must be considered in parameter estimation of aquifer properties. The WELLS code based on analytical pumping test solutions as described in Harp and Vesselinov (2011) renders the analyses of water-level fluctuations resulting from municipal well field operations possible. While analytical solutions are simple and elegant, this study suggests that a more sophisticated numerical groundwater model is required to capture the complexities of groundwater flow and water-level fluctuations in this highly heterogeneous glacial multi-aquifer/aquitard system. Such a groundwater model can then be utilized for parameter estimation to delineate the subsurface heterogeneity in hydraulic parameters. The creation of a more comprehensive groundwater model that is automatically calibrated with available data from municipal well fields should lead to improved optimization of operations and better policy decisions.

\section{Summary, findings and conclusions}

This paper presents the analyses of existing long-term pumping/injection and water-level records from a municipal well field in a complex multi-aquifer/aquitard system utilizing an approach proposed by Harp and Vesselinov (2011). The approach estimates homogeneous hydraulic properties of the aquifer in well fields consisting of multiple water-supply boreholes operating with rapidly varying pumping/injection rates. The fundamental principle behind this approach is the decomposition of pumping influences in monitoring boreholes and fingerprinting drawdown contributions to individual watersupply boreholes through the use of an analytical model. Here, a subset of pumping and water-level records from the Mannheim East Well Field provided by the Region of 
Waterloo in Waterloo, Ontario, Canada is analyzed, and water-level variations from a total of 14 monitoring boreholes are simulated individually by incorporating pumping/injection rate records of 13 water-supply boreholes in each simulation. The Theis (1935) solution is applied as the analytical model, and a set of transmissivity $(T)$ and storativity $(S)$ is obtained between each monitoring and water-supply boreholes by calibrating the analytical model. The estimated $T$ and $S$ values are first compared to results from previous aquifer tests conducted in the area showing good agreement. These values are then validated through simulation of water-level variations in nearby monitoring boreholes. The analysis presented in this work leads to the following major findings and conclusions:

1. The results reveal that long-term pumping/injection rates and corresponding water-level records from municipal well fields can be utilized to estimate hydraulic parameters such as $T$ and $S$ between water-supply and monitoring boreholes. The estimated hydraulic parameters are comparable to those estimated from previously conducted pumping tests. An important conclusion of this study is that these data should also be amenable to analysis with a more sophisticated numerical inverse model that treats the aquifer to be heterogeneous. Consideration of heterogeneity should yield more accurate aquifer parameters and ultimately lead to improved predictions of groundwater flow. Such a study should be attempted in the future.

2. Although the rapid water-level variations in some monitoring boreholes are not accurately captured by the Theis (1935) solution, it nevertheless captured the water-level fluctuations in virtually all monitoring boreholes quite well.

3. The geometric means of hydraulic parameters estimated from a single monitoring borehole with pumping/ injection taking place at neighboring water-supply boreholes may be useful in predicting drawdowns at nearby monitoring boreholes. Therefore, they may be more representative for existing water supply pumping/injection operations in comparison to values obtained from dedicated pumping tests that are typically conducted at a smaller scale.

4. Analyses of pressure decomposition plots provide fundamental insights into the pressure response of this investigated aquifer. The decomposition results indicate that three subdivided well sites in the Mannheim East Well Field may consist of different hydrogeologic conditions, and pressure propagation among them is compartmentalized. However, more monitoring locations and the analysis of data with more robust methods (e.g., hydraulic tomography) is suggested in order to analyze the influence area of water supply boreholes as well as heterogeneity within the aquifer using the same datasets.
5. Long-term decline in water levels are inferred from the analysis at some monitoring boreholes, and most of these boreholes are located at the ASR well site. The cause of this decline may be attributed to the withdrawals of groundwater that are not accounted for in this analysis (e.g., nearby quarries and private boreholes), but additional investigations are required to identify the sources that are causing this decline.

6. Finally, the analysis present in this paper provides fundamental insights into the drawdown responses of an aquifer subjected to complex pumping/injection regimes and has provided estimates of hydraulic parameters. While these parameters may be useful for a first-order analysis of aquifer responses, more sophisticated groundwater models should be calibrated to accurately characterize aquifer properties and their spatial variability utilizing the same datasets. More accurate hydraulic properties, their spatial variability and connectivity should lead to more accurate groundwater models which can be used to make improved predictions of drawdowns in municipal well fields, which in turn will lead to better policy decisions.

Acknowledgements This research was supported by a grant from the Region of Waterloo to the University of Waterloo. Additional support for Ning Luo was provided by the Discovery grant from the Natural Sciences \& Engineering Research Council of Canada (NSERC) awarded to Walter Illman. The assistance by Velimir V. Vesselinov to utilize the WELLS code is greatly appreciated. The authors thank Tammy Middleton and Eric Thuss from the Region of Waterloo for their assistance in accessing data used in this study. And finally, the authors thank the two reviewers Rob Soley and Andrew Hughes, and also the Hydrogeology Journal editors Martin Appold and Sue Duncan for their constructive comments and valuable suggestions that improved the manuscript.

Open Access This article is distributed under the terms of the Creative Commons Attribution 4.0 International License (http:// creativecommons.org/licenses/by/4.0/), which permits unrestricted use, distribution, and reproduction in any medium, provided you give appropriate credit to the original author(s) and the source, provide a link to the Creative Commons license, and indicate if changes were made.

\section{References}

Bajc AF, Shirota J (2007) Three-dimensional mapping of surficial deposits in the regional municipality of waterloo, southwestern Ontario groundwater resources study. Ontario Geological Survey, Groundwater Resources Study 3, OGS, Sudbury, ON, 41 pp

Berg SJ, Illman WA (2015) Comparison of hydraulic tomography with traditional methods at a highly heterogeneous site. Ground Water. doi:10.1111/gwat.12159

CH2M HILL (2003) Results of construction and testing of the ASR wells at the Mannheim Water Treatment Plant site: the Region of Waterloo. CH2M HILL, Englewood, CO

CH2M HILL, Papadopulos Associates (2003) Alder Creek Groundwater Study (final report): the Region of Waterloo. CH2M HILL, Englewood, CO 
Cooper HH, Jacob CE (1946) A generalized graphical method for evaluating formation constants and summarizing well field history. Am Geophys Union Trans 27:526-534

Doherty J (2005) PEST model-independent parameter estimation user mannal, 5th edn. Watermark, Brisbane, Australia

Golder Associates (2011) Tier 3 water budget and local area risk assessment: Mannheim Well Fields characterization. Golder, Burnaby BC, $95 \mathrm{pp}$

Hantush MS (1964) Hydraulic of wells. Adv Hydrosci 1:281-430

Hantush MS, Jacob CE (1955) Non-steady Green's functions for an infinite strip of leaky aquifer. EOS Trans Am Geophys Union 36(1): $101-112$

Harp DR, Vesselinov VV (2011) Identification of pumping influences in long-term water level fluctuations. Ground Water 49:12. doi:10. $1111 / j .1745-6584.2010 .00725 . x$

Karrow PF (1993) Quaternary geology, Stratford-Conestoga area, southern Ontario. Ontario Geological Survey, Sudbury, ON

Mansour MM, Hughes AG, Spink AEF, Riches J (2011) Pumping test analysis using a layered cylindrical grid numerical model in a complex, heterogeneous chalk aquifer. J Hydrol 401:14-21. doi:10. 1016/j.jhydrol.2011.02.005

Martin PJ, Frind EO (1998) Modeling a complex multi-aquifer system: the Waterloo moraine. Ground Water 36(4):679-690

Mathias SA, Butler AP (2006) Linearized Richards' equation approach to pumping test analysis in compressible aquifers. Water Resour Res 42:W06408. doi:10.1029/2005WR004680

Mishra PK, Neuman SP (2011) Saturated-unsaturated flow to a well with storage in a compressible unconfined aquifer. Water Resour Res 47(5):WR010177. doi:10.1029/2010WR010177
Mishra P, Vesselinov VV (2011) WELLS: multi-well variable-rate pumping-test analysis tool. https://gitlab.com/monty/wells. Accessed 7 Feb 2014

Moench AF (1997) Flow to a well of finite diameter in a homogeneous anisotropic water table aquifer. Water Resour Res 33(6):1397-1407

Neuman SP (1974) Effect of partial penetration on flow in unconfined aquifers considering delayed gravity response. Water Resour Res 10(1):303-312

Regional Municipality of Waterloo (2014) Region of Waterloo: hydrogeology \& source water-WRAS database design manual. Regional Municipality of Waterloo, Waterloo, ON

Sanchez-Vila X, Guadagnini A, Carrera J (2006) Representative hydraulic conductivities in saturated groundwater flow. Rev Geophys 44(3):rg000169. doi:10.1029/2005rg000169

Terraqua Investigation (1995) The study of the hydrogeology of the waterloo moraine: final report - the regional municipality of Waterloo. Terraqua Investigation, Tonasket WA

Theis CV (1935) The relation between the lowering of the piezometric surface and the rate and duration of discharge of a well using groundwater storage. Trans Am Geophys Union 16:519-524

Trow Dames \& Moore (1990) Mannheim aquifer short-term water supply development: Report prepared for the Region of Waterloo. Trow Dames \& Moore, Mississauga, ON

Wu C-M, Yeh T-CJ, Zhu J, Lee TH, Hsu N-S, Chen C-H, Sancho AF (2005) Traditional analysis of aquifer tests: comparing apples to oranges? Water Resour Res 41:12. doi:10.1029/2004WR003717

Yeh T-CJ, Lee CH (2007) Time to change the way we collect and analyze data for aquifer characterization. Ground Water 45(2):116-118. doi: 10.1111/j.1745-6584.2006.00292.x 